\title{
Cytotoxicity and Mitochondrial Effects of Phenolic and Quinone-Based Mitochondria-Targeted and Untargeted Antioxidants on Human Neuronal and Hepatic Cell Lines: A Comparative Analysis
}

\author{
Carlos Fernandes ${ }^{1, *}++^{\mathbb{D}}$, Afonso J. C. Videira ${ }^{1,+}{ }^{\text {, Caroline D. Veloso }}{ }^{1,+}{ }^{+}$, Sofia Benfeito ${ }^{2,+} \mathbb{D}$, Pedro Soares ${ }^{2}$, \\ João D. Martins ${ }^{1}{ }^{\mathbb{D}}$, Beatriz Gonçalves ${ }^{1}$, José F. S. Duarte ${ }^{1}$, António M. S. Santos ${ }^{1}$, Paulo J. Oliveira ${ }^{3} \mathbb{D}$, \\ Fernanda Borges $^{2} \mathbb{D}$, José Teixeira ${ }^{1,3}$ and Filomena S. G. Silva ${ }^{1, *}$
}

1 Mitotag, Biocant Park, Parque Tecnológico de Cantanhede, Núcleo 04, Lote 4, 3060-197 Cantanhede, Portugal; afonsovideira@mitotag.com (A.J.C.V.); velosocaroline@mitotag.com (C.D.V.); jdgmartins@gmail.com (J.D.M.); beatrizgoncalveess@gmail.com (B.G.); duartefeliciano@mitotag.com (J.F.S.D.); antoniomiguel@mitotag.com (A.M.S.S.); jose_8_teixeira@hotmail.com (J.T.)

2 CIQUP/Department of Chemistry and Biochemistry, Faculty of Sciences, University of Porto, 4169-007 Porto, Portugal; sofia_benfeito@hotmail.com (S.B.); pedro_hgsoares@hotmail.com (P.S.); fborges@fc.up.pt (F.B.)

check for updates

Citation: Fernandes, C.; Videira,

A.J.C.; Veloso, C.D.; Benfeito, S.;

Soares, P.; Martins, J.D.; Gonçalves, B.; Duarte, J.F.S.; Santos, A.M.S.; Oliveira, P.J.; et al. Cytotoxicity and

Mitochondrial Effects of Phenolic and Quinone-Based

Mitochondria-Targeted and

Untargeted Antioxidants on Human Neuronal and Hepatic Cell Lines: A Comparative Analysis. Biomolecules 2021, 11, 1605. https://doi.org/ 10.3390/biom11111605

Academic Editor: João S. Teodoro

Received: 16 September 2021

Accepted: 25 October 2021

Published: 29 October 2021

Publisher's Note: MDPI stays neutral with regard to jurisdictional claims in published maps and institutional affiliations.

Copyright: (c) 2021 by the authors. Licensee MDPI, Basel, Switzerland. This article is an open access article distributed under the terms and conditions of the Creative Commons Attribution (CC BY) license (https:/ / creativecommons.org/licenses/by/ $4.0 /)$.
3 CNC - Center for Neuroscience and Cell Biology, CIBB - Center for Innovative Biomedicine and Biotechnology, University of Coimbra, 3004-504 Coimbra, Portugal; pauloliv@cnc.uc.pt

* Correspondence: carlosfernandes@mitotag.com (C.F.); filomenasilva@mitotag.com (F.S.G.S.)

$\dagger$ These authors contributed equally to this work.

Abstract: Mitochondriotropic antioxidants $\left(\mathrm{MC}_{3}, \mathrm{MC}_{6.2}, \mathrm{MC}_{4}\right.$ and $\left.\mathrm{MC}_{7.2}\right)$ based on dietary antioxidants and analogs (caffeic, hydrocaffeic, trihydroxyphenylpropanoic and trihydroxycinnamic acids) were developed. In this study, we evaluate and compare the cytotoxicity profile of novel mitochondria-targeted molecules (generally known as MitoCINs) on human HepG2 and differentiated SH-SY5Y cells with the quinone-based mitochondria-targeted antioxidants MitoQ and SkQ 1 and with two non-targeted antioxidants, resveratrol and coenzyme $Q_{10}\left(C_{0} Q_{10}\right)$. We further evaluate their effects on mitochondrial membrane potential, cellular oxygen consumption and extracellular acidification rates. Overall, MitoCINs derivatives reduced cell viability at concentrations about six times higher than those observed with MitoQ and SkQ1. A toxicity ranking for both cell lines was produced: $\mathrm{MC}_{4}<M C_{7.2}<\mathrm{MC}_{3}<\mathrm{MC}_{6.2}$. These results suggest that $\mathrm{C}-6$ carbon linker and the presence of a pyrogallol group result in lower cytotoxicity. $\mathrm{MC}_{3}$ and $\mathrm{MC}_{6.2}$ affected the mitochondrial function more significantly relative to MitoQ, SkQ1, resveratrol and $\mathrm{CoQ}_{10}$, while $\mathrm{MC}_{4}$ and $\mathrm{MC}_{7.2}$ displayed around 100-1000 times less cytotoxicity than SkQ1 and MitoQ. Based on the mitochondrial and cytotoxicity cellular data, $\mathrm{MC}_{4}$ and $\mathrm{MC}_{7.2}$ are proposed as leads that can be optimized to develop safe drug candidates with therapeutic application in mitochondrial oxidative stress-related diseases.

Keywords: phenolic-based mitochondriotropic antioxidants; quinone-based mitochondriotropic antioxidants; non-targeted antioxidants

\section{Introduction}

Mitochondria are subcellular organelles responsible for most cellular adenosine triphosphate (ATP) production through oxidative phosphorylation (OXPHOS) [1]. During normal metabolism, mitochondria regulate reactive oxygen species (ROS) levels and the cell's redox state through the concerted action of antioxidant defenses. Under pathological conditions, mitochondrial dysfunction leads to increased ROS production and oxidative stress, a process associated with many health-related disorders, including neurodegenerative diseases, non-alcoholic fatty liver disease, cancer, or cardiovascular events, among others [2-4]. 
Current strategies to decrease excessive mitochondrial ROS production under pathological conditions involve the use of mitochondria-targeted antioxidants. The most popular approach is the conjugation of bioactive molecules to a linker and the lipophilic triphenylphosphonium $\left(\mathrm{TPP}^{+}\right.$) cation $[5,6]$. MitoQ (with a coenzyme Q core) and $\mathrm{SkQ}_{1}$ (with a plastoquinone core) $[7,8]$ are two among the most studied mitochondria-targeted antioxidants (Figure 1). In mitochondria, the quinone moiety is reduced to a quinol, and readily oxidized back to quinone, a process mediated by the respiratory chain, restoring the antioxidant function [8-10]. Nevertheless, both MitoQ and $\mathrm{SkQ}_{1}$ can also operate as prooxidants, inducing non-specific effects on mitochondria [8,11-13].

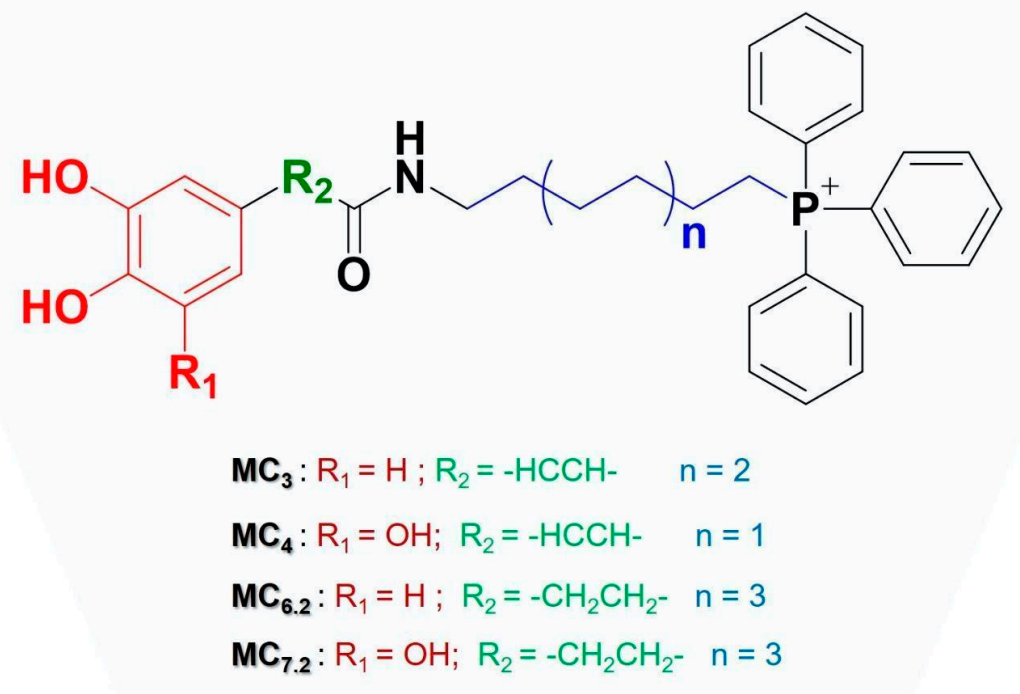<smiles>[R]C1=C([R2])C(=O)C(CCCCCCCCCC[P+](c2ccccc2)(c2ccccc2)c2ccccc2)=C([R3])C1=O</smiles>

MitoQ: $\mathrm{R}_{1}=\mathrm{R}_{2}=\mathrm{OCH}_{3} ; \mathrm{R}_{3}=\mathrm{CH}_{3}$

SkQ1: $R_{1}=R_{2}=C_{3} ; R_{3}=H$<smiles>COC1=C(OC)C(=O)C(C/C=C(\C)CC/C=C(\C)CCC=C(C)C)=C(C)C1=O</smiles>

Coenzyme $\mathbf{Q}_{10}$

Resveratrol

Figure 1. Chemical structures of the mitochondria-targeted (the counterion was omitted for simplicity) and non-targeted antioxidants under study.

After promising preclinical studies, the two quinone-based antioxidants entered into clinical trials for diseases such as hepatitis C (NCT00433108), diastolic dysfunction (NCT03586414), Parkinson's disease (NCT00329056), multiple sclerosis (NCT03166800), 
treatment of metabolic dysfunction in asthma (NCT04026711), and dry-eye syndrome (NCT03764735 and NCT04206020) (http:/ / clinicaltrials.gov (accessed on 10 September 2021). However, none of the two mitochondria-targeted drug candidates were approved by the Food and Drug Administration (FDA). This may have been related to their failure to reach the primary efficacy endpoints [14]. Thus, new, safer and more effective mitochondriatargeted antioxidants must be developed using other antioxidant cores, such as those of dietary polyphenols. The intake of dietary polyphenols is beneficial due to their antioxidant properties and ability to regulate cellular oxidative stress events. Different mechanisms are proposed for the antioxidant effects of polyphenols: the removal of ROS by direct scavenging of free radicals, upregulation of the activity of ROS-removing enzymes and endogenous antioxidants, chelation of transition metals, and direct inhibition of ROSproducing enzymes [15]. The latter three mechanisms are the most likely to be prevalent physiologically [15].

Among dietary antioxidants, hydroxycinnamic acids (HCAs), such as caffeic or ferulic acids, showed a relevant antioxidant performance in cell-free and cell-based models [16] However, they have bioavailability constraints, mainly related to their physicochemical properties, including low lipophilicity [17-19], and unspecific intracellular accumulation. The latter caveat implies a reduced accumulation on intracellular sites of augmented ROS production, such as mitochondria [20-22].

To overcome HCAs' setbacks, and as an alternative to MitoQ and $\mathrm{SkQ}_{1}$, a library of mitochondriotropic antioxidants based on HCAs and its analogs was developed $[23,24]$. The novel mitochondria-targeted HCA family known as MitoCINs or AntiOxCINs also TPP ${ }^{+}$ as a carrier and showed a higher antioxidant, iron-chelating properties, the capacity to increase glutathione (GSH) concentrations, and similar or higher mitochondrial accumulation capacity when compared with MitoQ [23]. In a previous study, four novel mitochondriatargeted HCAs, namely $\mathrm{MC}_{3}, \mathrm{MC}_{4}, \mathrm{MC}_{6.2}$ and $\mathrm{MC}_{7.2}$ (Figure 1), were described as having unique properties to prevent progressive mitochondrial dysfunction [25].

Extending our previous studies, the novelty in the present work is the comparison of the cytotoxicity and mitochondrial profile of selected MitoCINs library compounds $\left(\mathrm{MC}_{3}, \mathrm{MC}_{6.2}, \mathrm{MC}_{4}\right.$ and $\mathrm{MC}_{7.2}$ ) (Figure 1), with the mitochondria-targeted antioxidants MitoQ and $\mathrm{SkQ}_{1}$ (Figure 1). Furthermore, we compared the effects of the four MitoCINs molecules with two non-targeted antioxidants that have been tested under clinical trials [26-28], namely resveratrol (NCT01914081, NCT03933163) and CoQ 10 (NCT04780074, NCT04038034) (Figure 1).

Resveratrol is a phenolic compound with antioxidant properties and beneficial effects in age-related diseases $[29,30]$, including neurodegeneration [31]. Although resveratrol can protect neurons from oxidative stress extracellular toxins and insults associated with neurodegenerative disorders through sirtuin 1 activation [32-34], it has low mitochondrial accumulation and low bioavailability [35]. Coenzyme $\mathrm{Q}_{10}\left(\mathrm{CoQ}_{10}\right)$ has been extensively proposed as a potential therapeutic agent for different neurodegenerative and hepatic diseases; however, its low bioavailability forces it to be administered in substantially high doses, resulting in side-effects [36]. Disappointing results were obtained in some of the clinical trials performed using $\mathrm{CoQ}_{10}[37,38]$ and resveratrol $[39,40]$.

For the cytotoxicity comparison of the different classes of compounds, we used HepG2 and differentiated SH-SY5Y cells as in vitro models, since they are often used in the preclinical safety assessment of drug candidates in hepatic and neurodegenerative diseases, respectively [41-43]. Although HepG2 is a human hepatoma cell line, it is one of the most commonly used cell models in cytotoxicity screening of different compounds due to its stable phenotype, high availability, easy handling, and phase I and phase II metabolizing activities [44].

The objective of this study was to advance our knowledge of the cytotoxicity of the selected MitoCINs at the mitochondrial level in two different cell systems, compared with two mitochondria-targeted and two untargeted antioxidants, which have been used in 
clinical trials. The results of our work will contribute to the development of novel and more effective mitochondrial therapies against neurodegenerative and hepatic diseases.

\section{Material and Methods}

\subsection{Reagents and Cells}

All reagents and solvents for chemical synthesis were purchased from Merck Life Science S.L.U (Sintra, Portugal), TCI (Zwijndrecht, Belgium) and Carlo Erba Reactifs (Barcelona, Spain) and used without any further purification. Dulbecco's Modified Eagle's Medium (DMEM-D5030), L-Glutamine (G3126), sodium bicarbonate (S6014), sodium pyruvate (P5280), 2-[4-(2-hydroxyethyl)piperazin-1-yl]ethanesulfonic acid (HEPES) (H3375), sulforhodamine B sodium salt (S9012), hydrochloric acid 37\% (30721), resazurin sodium salt (R7017), dimethyl sulfoxide (DMSO) (34869), carbonyl cyanide 4-(trifluoromethoxy) phenylhydrazone (FCCP) (C2920), rotenone (R8875) and antimycin A (A8674) were obtained from Merck Life Science S.L.U (Sintra, Portugal). Caffeic acid, hydrocaffeic acid, trihydroxycinnamic acid (TriOH), trihydroxyphenylpropanoic acid (hydro-TriOH), resveratrol (R5010) and $\mathrm{CoQ}_{10}$ (C9538) were purchased from Sigma (Sintra, Portugal). Fetal bovine serum (FBS) (10270106), penicillin-streptomycin (15140122), tetramethylrhodamine, methyl ester, perchlorate (TMRM) (T668), Hoechst 33342, Trihydrochloride, Trihydrate (H1399) were obtained from Gibco-Invitrogen (Waltham, MA, USA). From VWR (Amadora, Portugal), we obtained the d-glucose (0188). Glacial acetic acid (A/0400/PB15), methanol $(\mathrm{M} / 4056 / 17)$, sodium hydroxide (P/5640/60) were obtained from Fisher Chemical (Porto Salvo, Portugal). Tris base was obtained from ChemCruz (sc-3715) (Heidelberg, Germany). The CellTiter-Glo ${ }^{\circledR}$ Luminescent Cell Viability Assay (PROMG7571) was provided by Promega (Madison, WI, USA). Seahorse XFe96 FluxPak (102416-100) was obtained from Agilent (Santa Clara, CA, USA). Oligomycin (495455) was obtained from Calbiochem (Darmstadt, Germany).

\subsection{Chemical Synthesis}

\subsubsection{General Conditions}

The progression of the synthetic reactions was followed by thin-layer chromatography (TLC), as previously described by Teixeira et al. [23]. The work-up process for each crude product was performed as described $[23,25,45]$. The purification of the compounds was performed by flash column chromatography using silica gel $60(0.040-0.063 \mathrm{~mm})$ and/or recrystallization.

The compound's structural characterization was produced by ${ }^{1} \mathrm{H}$ and ${ }^{13} \mathrm{C}$ nuclear magnetic resonance (NMR) spectra, electron impact mass spectra (EI-MS) and electrospray ionization (ESI), in the conditions reported by Benfeito et al. [25].

\subsubsection{General Procedure for Synthesis of $\mathrm{TPP}^{+}$-Based Antioxidants}

The synthetic methodologies and spectroscopic characterization data (Nuclear Magnetic Resonance Spectroscopy and Mass Spectrometry) of the phenolic mitochondriotropic antioxidants MitoCINs $\left(\mathrm{MC}_{3}, \mathrm{MC}_{4}, \mathrm{MC}_{6.2}\right.$ and $\mathrm{MC}_{7.2}$ ) were previously described by Benfeito et al. $[23,25]$; the synthesis of the quinone-based mitochondriotropic antioxidants (MitoQ and $\mathrm{SKQ}_{1}$ ) was based on the procedures reported by James et al. [12] and Korshunova et al. [46].

\subsection{Cell Culture Conditions and Treatments with Compounds \\ 2.3.1. HepG2 Cells}

HepG2 cells were cultured in DMEM (D5030) supplemented with 10\% (v/v) FBS, 1\% $(v / v)$ antibiotic penicillin-streptomycin, $3.7 \mathrm{~g} / \mathrm{L}$ sodium bicarbonate, $0.876 \mathrm{~g} / \mathrm{L}$ L-glutamine, $0.11 \mathrm{~g} / \mathrm{L}$ sodium pyruvate and $0.90 \mathrm{~g} / \mathrm{L}$ glucose. These cells were also supplemented with $1.19 \mathrm{~g} / \mathrm{L}$ HEPES. All cells were cultured in monolayer in adherent tissue culture dishes at $37^{\circ} \mathrm{C}$ in a humidified atmosphere of $5 \% \mathrm{CO}_{2}$. Cells were subjected to trypsinization using standard methods when reaching $80-90 \%$ confluence and were only used between passages 
5 to 25 in cultures in log-phase growth. HepG2 were seeded at $3.0 \times 10^{4}$ cells $/ \mathrm{cm}^{2}$ for extracellular flux analysis and TMRM assays, and at $6.0 \times 10^{4} \mathrm{cells} / \mathrm{cm}^{2}$ for the remaining experiments.

\subsubsection{Differentiated SH-SY5Y Cells}

SH-SY5Y cells were cultured in DMEM (D5030) supplemented with 10\% $(v / v)$ FBS, $1 \%(v / v)$ antibiotic penicillin-streptomycin, $3.7 \mathrm{~g} / \mathrm{L}$ sodium bicarbonate, $0.876 \mathrm{~g} / \mathrm{L} \mathrm{L}$ glutamine, $0.11 \mathrm{~g} / \mathrm{L}$ sodium pyruvate, $4.5 \mathrm{~g} / \mathrm{L}$ glucose and $1.19 \mathrm{~g} / \mathrm{L}$ HEPES. Cells were cultured in monolayer in adherent tissue culture dishes at $37^{\circ} \mathrm{C}$ in a humidified atmosphere of $5 \% \mathrm{CO}_{2}$ and were passaged by trypsinization using standard methods when reaching $80-90 \%$ confluence, only being used between passages 14 to 25 in cultures in log-phase growth. For the differentiation process, SH-SY5Y cells were seeded $\left(2.4 \times 10^{4} \mathrm{cells} / \mathrm{cm}^{2}\right)$ with cell culture medium supplemented with retinoic acid (RA) $10 \mu \mathrm{M}$ for 3 days. On the third day, the cell culture medium was replaced by a fresh one supplemented with 12-otetradecanoylphorbol-13-acetate (TPA) $80 \mathrm{nM}$, allowing the cells to grow in this medium for an additional period of three days before starting the experimental procedure [47].

\subsection{Compound Treatments}

HepG2 cells were seeded for $24 \mathrm{~h}$, during which they reached $40-60 \%$ confluence. SH-SY5Y cells were seeded and subjected to the differentiation protocol mentioned above (Section 2.3.2). Cells were then incubated with increasing concentrations of MitoCIN compounds $\left(\mathrm{MC}_{3}, \mathrm{MC}_{6.2}, \mathrm{MC}_{4}, \mathrm{MC}_{7.2}\right)$, the two mitochondria-targeted antioxidants (MitoQ and $\mathrm{SkQ}_{1}$ ) and the two non-targeted antioxidants (resveratrol, $\mathrm{CoQ}_{10}$ ). Stock solutions of all tested compounds at a final concentration of $100 \mathrm{mM}$ were prepared in DMSO, except for $\mathrm{CoQ}_{10}$, which was dissolved in chloroform. The maximal concentration of all solvents used in the cellular treatments was $0.1 \%$. As a secondary control, we tested the cytotoxicity of the MitoCIN parentals (caffeic acid, hydrocaffeic acid, $\mathrm{TriOH}$, hydro-TriOH) and the corresponding alkyl-TPP chains (TPP-C6, TPP-C8 and TPP-C10) for $48 \mathrm{~h}$ in a low-glucose culture medium. The experiments with MitoCIN compounds, mitochondrial-targeted antioxidants, non-targeted antioxidants, MitoCIN parentals, and alkyl-TPP chains were performed in parallel under the same experimental conditions. Cellular metabolic activity and cell mass were assessed using resazurin reduction and a sulforhodamine B (SRB) assay. Intracellular ATP levels and mitochondrial polarization were determined by commercial fluorescent dyes. Cellular oxygen consumption (OCR) and Extracellular Acidification Rate (ECAR) were measured using a Seahorse XFe96 Extracellular Flux Analyzer.

\subsection{Cell Mass}

Sulforhodamine B was used for the measurement of cellular protein content, which is proportional to cell mass [48]. After $48 \mathrm{~h}$ of treatment, the culture medium was removed and the wells were washed with PBS (1X). With $100 \mu \mathrm{L}$ of $1 \%(v / v)$ acetic acid in methanol, the cells were fixed overnight at $-20^{\circ} \mathrm{C}$. After discarding the fixation solution, the plates were dried in an incubator at $37^{\circ} \mathrm{C}$. Next, we added $70 \mu \mathrm{L}$ of SRB $0.05 \%(w / v)$ and incubated it at $37^{\circ} \mathrm{C}$ for $1 \mathrm{~h}$. The wells were washed with $1 \%(v / v)$ of acetic acid in water and dried again. Lastly, $125 \mu \mathrm{L}$ of $10.5 \mathrm{mM}$ tris- $\mathrm{NaOH}$ was used to solubilize the SRB and absorbance was measured at $510 \mathrm{~nm}$, subtracting background measured at $620 \mathrm{~nm}$ in the CLARIOstar Plus microplate reader (BMG Labtech, Ortenberg, Germany).

\subsection{Cell Metabolic Activity}

Resazurin reduction assay was used to determine the cells' metabolic activity [48]. After the incubation time, the culture medium was removed, and the cells were incubated with $10 \mu \mathrm{g} / \mathrm{mL}$ of resazurin solution for $1 \mathrm{~h}$ to $1 \mathrm{~h} 30$ at $37^{\circ} \mathrm{C}$ and $5 \% \mathrm{CO}_{2}$. The reduction of resazurin to resorufin was measured fluorometrically at $540 \mathrm{~nm}$ excitation and $590 \mathrm{~nm}$ emission in the CLARIOstar Plus microplate reader (BMG Labtech, Ortenberg, Germany) 


\subsection{Intracellular ATP Levels}

The cells were seeded in $150 \mu \mathrm{L}$ of cell culture medium in a white opaque bottom 96-well plate for $48 \mathrm{~h}$. After the incubation time, intracellular ATP levels were measured using CellTiter-Glo ${ }^{\circledR}$ Luminescent Cell Viability Assay (Promega, Madison, WI, USA). For that purpose, the culture medium was removed from each well and mixed with an equal amount of the CellTiter-Glo reagent. After that, $100 \mu \mathrm{L}$ of the mixture was added to each well and, in a microplate reader, the plate was mixed for $2 \mathrm{~min}$ to induce cell lysis. After $10 \mathrm{~min}$ of incubation, a luminescent signal proportional to the amount of ATP present was generated and measured in a CLARIOstar Plus microplate reader (BMG Labtech, Ortenberg, Germany). The ATP standard curve was generated following the manufacturer's instructions.

\subsection{Mitochondrial Polarization}

TMRM staining is a fluorescent dye that monitors mitochondrial function and mitochondrial membrane electric potential [49]. TMRM fluorescence signal intensity is proportional to the mitochondrial membrane potential. After cell culture and treatment with the different compounds in black 96-well plates, TMRM was added to each well to provide a final working concentration of $100 \mathrm{nM}$ dye in cell culture medium without FBS. Simultaneously, $1 \mathrm{mg} / \mathrm{mL}$ of Hoechst 33342 was added to label the nuclei and to normalize the results. After $25 \mathrm{~min}$ of incubation at $37^{\circ} \mathrm{C}$ and $5 \% \mathrm{CO}_{2}$, the cell culture media with TMRM and Hoechst 33342 was removed and replaced by $100 \mu \mathrm{L}$ of pre-warmed cell culture medium without FBS. The fluorescence signal was recorded using a $548 \mathrm{~nm}$ excitation wavelength and a $575 \mathrm{~nm}$ emission wavelength in the CLARIOstar Plus microplate reader (BMG Labtech, Ortenberg, Germany).

\subsection{Cellular Oxygen Consumption and Extracellular Acidification Rates}

HepG2 cells were seeded in pre-coated (with collagen I $0.15 \mathrm{mg} / \mathrm{mL}$ ) Agilent Seahorse XF96 cell culture microplates. SH-SY5Y cells were seeded in the same type of XF96 cell culture microplate without the pre-coating step. The cell densities were as follows: HepG2 $1 \times 10^{4}$ cells $/ 80 \mu \mathrm{L} /$ well; SH-SY5Y $5.5 \times 10^{3}$ cells $/ 103 \mu \mathrm{L} /$ well. OCR and ECAR were measured at $37^{\circ} \mathrm{C}$ using a Seahorse XFe96 Extracellular Flux Analyzer (Agilent Scientific Instruments, Santa Clara, CA, USA).

The day before the experiment, an XFe96 sensor cartridge for each cell plate was placed in a 96 well calibration plate with $200 \mu \mathrm{L}$ /well of calibration buffer and left to hydrate overnight at $37^{\circ} \mathrm{C}$. On the following day, medium from the plates was replaced with $175 \mu \mathrm{L}$ /well of pre-warmed, low-buffered, serum-free minimal DMEM medium, supplemented with glucose, glutamine and sodium pyruvate, with $\mathrm{pH}$ adjusted to 7.4 and incubated at $37^{\circ} \mathrm{C}$ for $1 \mathrm{~h}$ to allow the temperature and $\mathrm{pH}$ of the medium to reach equilibrium before the first-rate measurement. Oligomycin, FCCP, rotenone (ROT) and antimycin A (AA) were prepared in low-buffered serum-free DMEM medium, supplemented with glucose, glutamine and sodium pyruvate and the $\mathrm{pH}$ was adjusted to 7.4. These compounds were loaded into cartridge ports $\mathrm{A}, \mathrm{B}$ and $\mathrm{C}$ (ROT/AA), respectively: HepG2 ( $2 \mu \mathrm{M}$ oligomycin, $2 \mu \mathrm{M}$ FCCP, $1 \mu \mathrm{M}$ ROT / AA) and SH-SY5Y ( $2 \mu \mathrm{M}$ oligomycin, $0.5 \mu \mathrm{M}$ FCCP, $1 \mu \mathrm{M}$ ROT / AA). After $1 \mathrm{~h}$ of calibration, the 96 well calibration plate was replaced by the cell plate. Oligomycin, FCCP and ROT / AA were then injected by the XFe96 Analyzer into each well at sequential times. The analysis of the OCR-related parameters was performed using the Agilent Seahorse XF Cell Mitostress test report generator software (version 2.6.0).

\subsection{Data Preprocessing and Statistical Analysis}

\subsubsection{Data Preprocessing}

The data from all the experiments were preprocessed using the spreadsheet program Google sheets and R statistical software. 
The data outputs from CLARIOstar Plus microplate reader (BMG Labtech, Ortenberg, Germany) and Seahorse XFe96 Extracellular Flux Analyzer (Agilent Scientific Instruments, Santa Clara, CA, USA) were compiled into standardized data sets where the background signals were subtracted and the cross-plate systematic effects were mitigated by normalizing all the values to a percentage score using the following formula:

$$
\text { Percentage of control }(\%)=\frac{t-\underline{x}_{0}}{\underline{x}_{1}-\underline{x}_{0}} \times 100
$$

where $t$ is the absorbance value of the treatment well and $\underline{x}_{0}$ and $\underline{x}_{1}$ are the background and control means, respectively, of the absorbance values of the treatment plate.

All plate replicates per condition were summarized by their mean values to obtain the respective biological observations of the treatments.

Observations outside 1.5 times the interquartile range (IQR) of the sample's first and third quartiles were considered outliers and not considered for the analysis.

\subsubsection{Statistical Analysis}

Statistical analysis was performed using $\mathrm{R}$ statistical software. The comparisons between groups were performed between each compound and the untreated control or between different compounds, using Welch's t-test. $p$-values were corrected using Bonferroni's methodology and deemed statistically significant if $<0.05$.

\section{Results}

\subsection{Chemistry}

The mitochondriotropic antioxidants $\left(\mathrm{MC}_{3}, \mathrm{MC}_{4}, \mathrm{MC}_{6.2}\right.$ and $\left.\mathrm{MC}_{7.2}\right)$ and their respective intermediates were synthesized according to the method used by Benfeito et al. $[23,25]$, while MitoQ and SkQ1 were prepared based on the procedures described by James et al. [12] and Korshunova et al. [46], respectively. The structural characterization was performed by NMR $\left({ }^{1} \mathrm{H},{ }^{13} \mathrm{C}\right.$ and DEPT) and mass spectroscopy (EI-MS and ESI-MS) techniques, thereby confirming their chemical identity. The desired compounds were obtained in moderate yields $(>40 \%)$ with a grade of purity higher than $99 \%$, which was determined through high-performance liquid chromatography (data not shown).

\subsection{Comparative Cytotoxicity between MitoCINs and Targeted-and Non-Targeted Antioxidants}

$\mathrm{MC}_{3}, \mathrm{MC}_{6.2}, \mathrm{MC}_{4}$ and $\mathrm{MC}_{7.2}$ are caffeic, hydrocaffeic, trihydroxyphenylpropanoic and trihydroxycinnamic acid-based derivatives linked by an alkyl chain to TPP cation, respectively (Figure 1). Their cytotoxicity was evaluated and compared with MitoQ, SkQ 1 , resveratrol and $\mathrm{CoQ}_{10}$ in HepG2 and differentiated SH-SY5Y cells by measuring alterations in cell mass, metabolic viability and intracellular ATP levels. Cells were incubated with the compounds at concentrations between 1-100 $\mu \mathrm{M}$ for $48 \mathrm{~h}$.

$\mathrm{MC}_{3}$ significantly decreased HepG2 cell mass and metabolic activity at concentrations above $12.5 \mu \mathrm{M}$ (Figure 2A) and $25 \mu \mathrm{M}$ (Figure 3A), compared to untreated cells, respectively. In agreement with this, $\mathrm{MC}_{3}$ significantly decreased HepG2 ATP levels at concentrations above $12.5 \mu \mathrm{M}$ compared to untreated cells (Figure $4 \mathrm{~A}$ ). $\mathrm{MC}_{3}$ also decreased differentiated SH-SY5Y cell mass (Figure 2C) and metabolic activity (Figure 3C) at concentrations above $100 \mu \mathrm{M} . \mathrm{MC}_{3}$ showed a dual effect in differentiated SH-SY5Y cells, increasing ATP levels at concentrations of $6.3 \mu \mathrm{M}$ and decreasing them at $100 \mu \mathrm{M}$, compared to untreated cells (Figure 4C).

$\mathrm{MC}_{6.2}$ significantly decreased HepG2 cell mass at concentrations above $6.3 \mu \mathrm{M}$, compared to untreated cells (Figure 2A). Our results also showed that $\mathrm{MC}_{6.2}$ decreased cell metabolic activity (Figure 3A) and intracellular ATP levels (Figure 4A) at concentrations above $12.5 \mu \mathrm{M}$. In differentiated SH-SY5Y cells, $\mathrm{MC}_{6.2}$ showed a dual effect, increasing cell mass at $3.2 \mu \mathrm{M}$ and decreasing it at $25 \mu \mathrm{M}$ (Figure $2 \mathrm{C}$ ). $\mathrm{MC}_{6.2}$ also showed a dual effect in differentiated SH-SY5Y cells, increasing their metabolic activity at $6.3 \mu \mathrm{M}$ and decreasing it 
at $25 \mu \mathrm{M}$ (Figure 3C). As observed for $\mathrm{MC}_{3}, \mathrm{MC}_{6.2}$ also increased intracellular ATP levels at $3.2 \mu \mathrm{M}$ and decreased them at $25 \mu \mathrm{M}$ (Figure $4 \mathrm{C}$ ).

No alterations were observed in HepG2 cell mass treated with $\mathrm{MC}_{4}$ compared to untreated cells at concentrations up to $100 \mu \mathrm{M}$ (Figure 2A). Cellular metabolic activity significantly increased at $6.3 \mu \mathrm{M}$ and $50 \mu \mathrm{M}$ (Figure 3A). Our results also showed that the cells treated with $\mathrm{MC}_{4}$ at concentrations up to $100 \mu \mathrm{M}$ presented similar values of intracellular ATP levels compared to untreated cells (Figure 4A). Additionally, $\mathrm{MC}_{4}$ increased differentiated SH-SY5Y cell mass at 12.5 and $25 \mu \mathrm{M}$ (Figure 2C), while not affecting the metabolic activity of the differentiated SH-SY5Y cells (Figure 3C). As with the metabolic activity, $\mathrm{MC}_{4}$ treatment did not affect the intracellular ATP levels of the differentiated SH-SY5Y cells (Figure 4C).
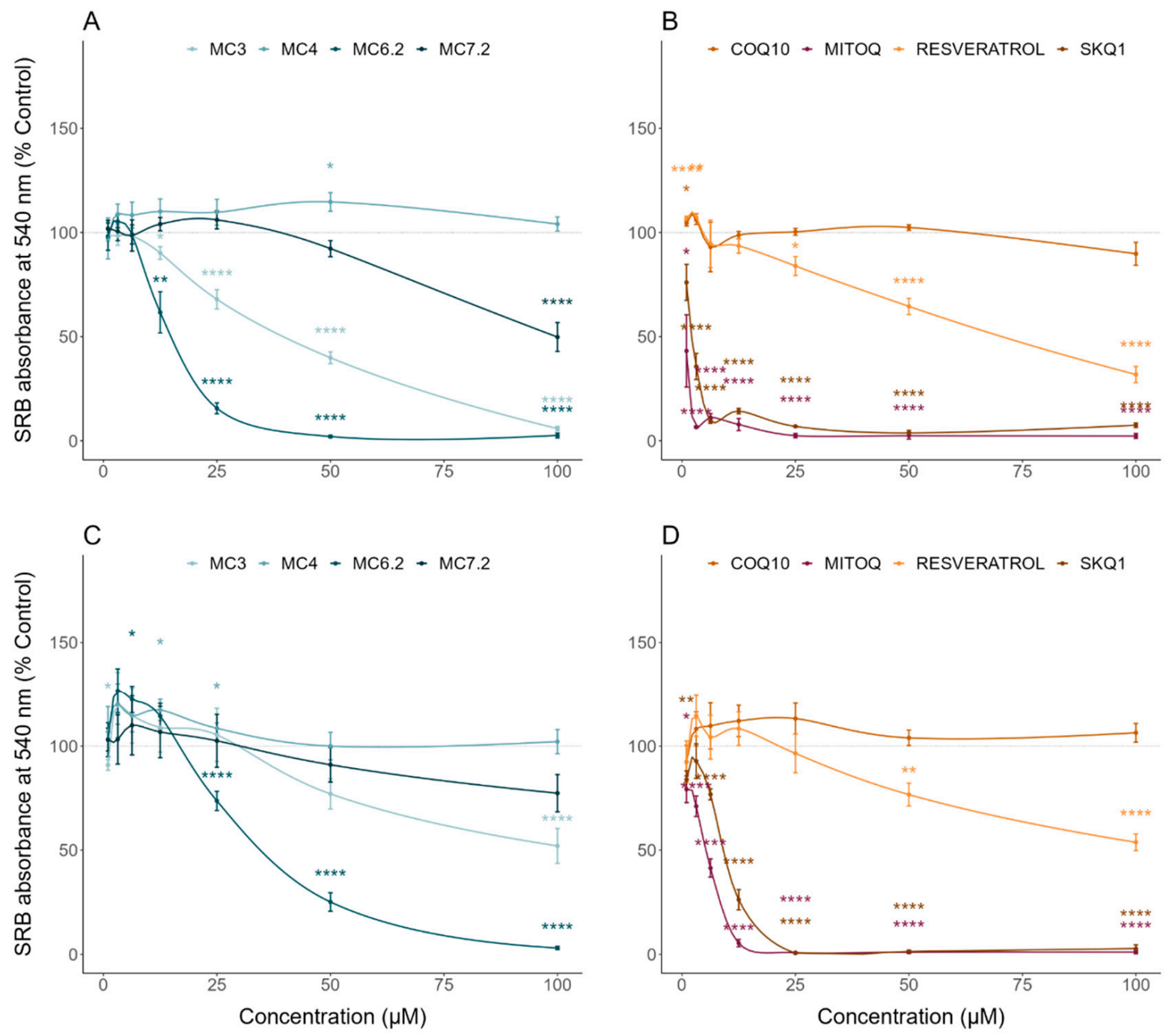

Figure 2. Effect of MitoCINs, quinone-based mitochondria-targeted and non-targeted antioxidants on cell mass. Human Caucasian hepatocyte carcinoma (HepG2, (A,B)) and differentiated human neuroblastoma (SH-SY5Y, $(\mathbf{C}, \mathbf{D})$ ) were treated with increasing concentrations of the different molecules for a period of $48 \mathrm{~h}$ and cellular mass was evaluated using Sulforhodamine B (SRB) assay. Data are the mean \pm SE of four independent experiments and the results are expressed as a percentage of the control. Statistically significant differences between control (CTL) and treated groups were evaluated as described in the Materials and Methods section. ${ }^{* * * *} p<0.0001,{ }^{* *} p<0.01$ and ${ }^{*} p<0.05$ compared to the respective control (CTL). 

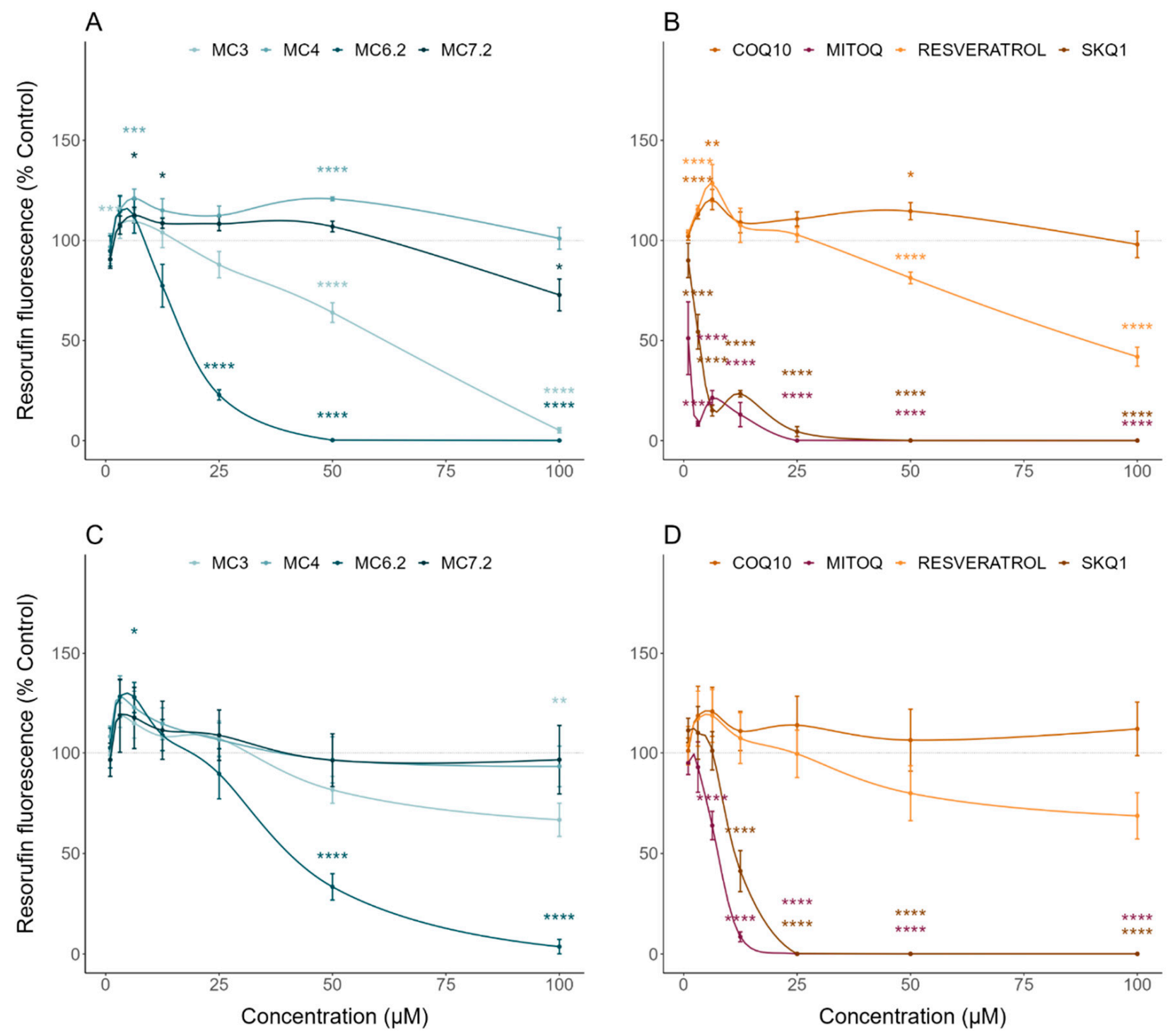

Figure 3. Effect of MitoCINs, quinone-based mitochondria-targeted and non-targeted antioxidants on metabolic activity. Human Caucasian hepatocyte carcinoma (HepG2, (A,B)) and differentiated human neuroblastoma (SH-SY5Y, (C,D)) were treated with increasing concentrations of the different molecules for a period of $48 \mathrm{~h}$ and metabolic activity was evaluated using resazurin reduction assay. Data are the mean $\pm \mathrm{SE}$ of four independent experiments and the results are expressed as a percentage of the control (control $=100 \%$ ). Statistically significant differences between control (CTL) and treated groups were evaluated using a $t$-test. ${ }^{* * *} p<0.0001,{ }^{* *} p<0.001,{ }^{* *} p<0.01$ and ${ }^{*} p<0.05$ compared to the respective control (CTL).

HepG2 cells treated with $\mathrm{MC}_{7.2}$ showed a decrease in cell mass at $100 \mu \mathrm{M}$ compared to the untreated cells (Figure 2A). On the other hand, cells treated with $\mathrm{MC}_{7.2}$ presented decreased metabolic activity at $100 \mu \mathrm{M}$ (Figure 3A). However, $\mathrm{MC}_{7.2}$ did not alter intracellular ATP levels at concentrations up to $100 \mu \mathrm{M}$ (Figure 4A). In the differentiated SH-SY5Y cells, no alterations were observed in cell mass (Figure 2C) and metabolic activity (Figure 3C) up to $100 \mu \mathrm{M}$. Additionally, $\mathrm{MC}_{7.2}$ increased intracellular ATP levels at concentrations between 3.2-25 $\mu \mathrm{M}$ and decreased them at $100 \mu \mathrm{M}$ compared to untreated cells (Figure $4 \mathrm{C}$ ). Together, these results suggest that $\mathrm{MC}_{4}$ and $\mathrm{MC}_{7.2}$ presented lower cytotoxicity than $\mathrm{MC}_{3}$ and $\mathrm{MC}_{6.2}$ in both HepG2 and differentiated SH-SY5Y cells.

To obtain further information on the cytotoxicity mechanisms of the four MitoCIN molecules, we also measured the cytotoxicity of the parental compounds of all four MitoCINs, as well as their alkylTPP constituents. 

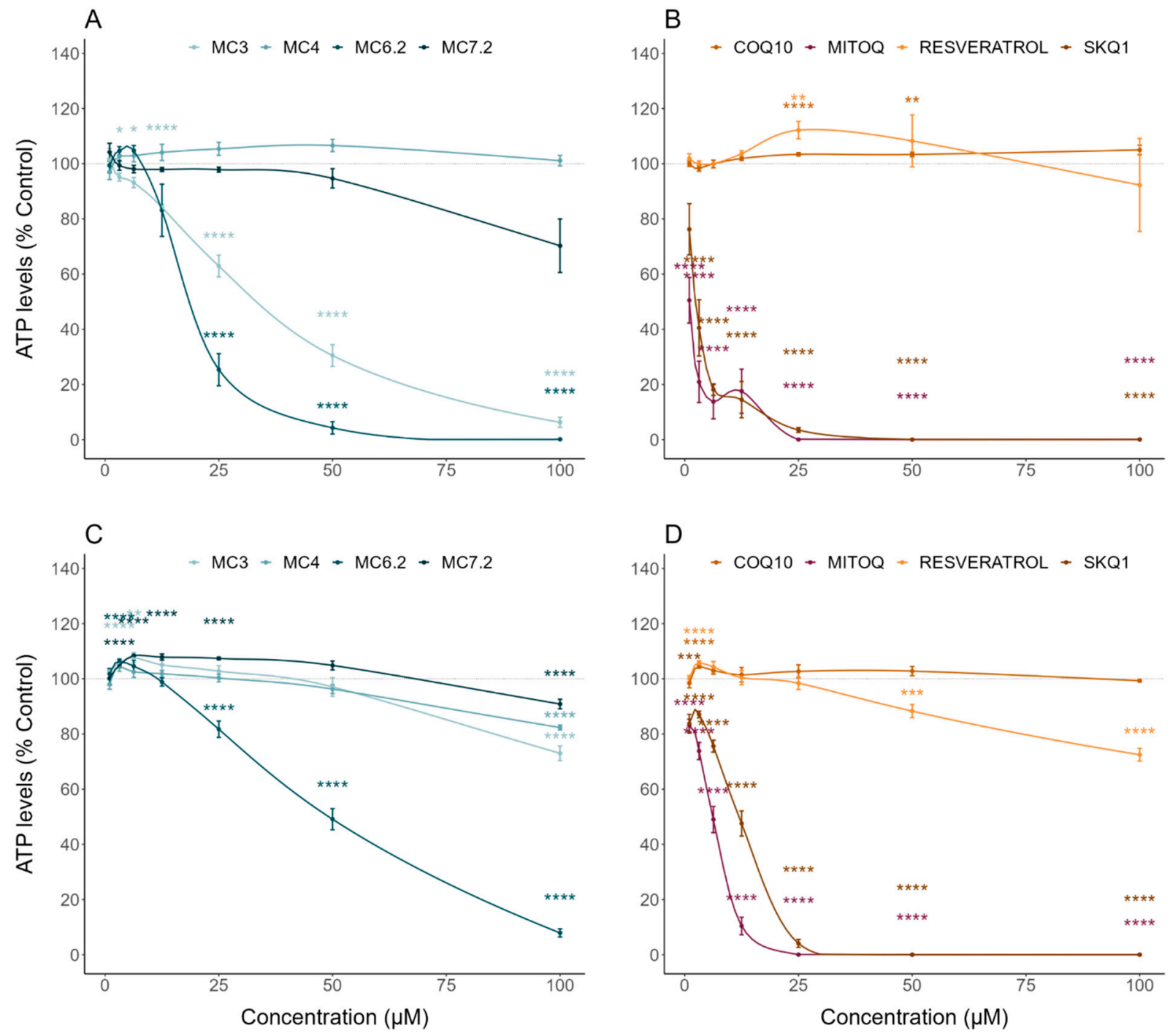

Figure 4. Effect of MitoCINs, quinone-based mitochondria-targeted and non-targeted antioxidants on ATP intracellular concentrations. Human Caucasian hepatocyte carcinoma (HepG2, (A,B)) and differentiated human neuroblastoma (SHSY5Y, (C,D)) were treated with increasing concentrations of the different molecules for a period of $48 \mathrm{~h}$, and intracellular ATP levels were evaluated using CellTiter-Glo ${ }^{\circledR}$ Luminescent Cell Viability Assay. Data are the mean \pm SE of three independent experiments and the results are expressed as a percentage of the control (control $=100 \%$ ). Statistically significant differences between control (CTL) and treated groups were evaluated using a $t$-test. ${ }^{* * *} p<0.0001,{ }^{* * *} p<0.001$, $^{* *} p<0.01$ and * $p<0.05$ compared to the respective control (CTL).

The caffeic, hydrocaffeic acid, hydro-TriOH and TriOH parental compounds, up to $100 \mu \mathrm{M}$, did not cause any alterations in HepG2 cell mass (Figure S1A). Additionally, the HepG2 cells treated with caffeic acid, hydrocaffeic acid and hydro-TriOH showed higher metabolic activity compared to the untreated cells (caffeic acid: $6.3,25$ and $50 \mu \mathrm{M}$, hydrocaffeic acid: 6.3 and $50 \mu \mathrm{M}$ and hydro-TriOH: 3.2, 6.3, 25 and $50 \mu \mathrm{M}$ ), while TriOH did not affect the metabolic activity (Figure S2A). Additionally, hydrocaffeic acid increased HepG2 ATP levels at concentrations of 25 and $100 \mu \mathrm{M}$. However, no alterations in ATP levels were observed in the HepG2 cells treated with caffeic acid, TriOH and HydroTriOH at concentrations up to $100 \mu \mathrm{M}$ (Figure S3A). Similarly, from the data attained on HepG2 cells, no alterations were observed in the differentiated SH-SY5Y cell mass when treated with caffeic, hydroTriOH and TriOH at concentrations up to $100 \mu \mathrm{M}$ (Figure S1C), although hydrocaffeic acid differentiated SH-SY5Y at $12.5 \mu \mathrm{M}$ compared to untreated cells (Figure S1C). No alterations in metabolic activity were observed in the differentiated SH-SY5Y cells treated with caffeic acid, hydrocaffeic acid and hydro-TriOH at concentrations up to $100 \mu \mathrm{M}$, unlike 
TriOH, which reduced metabolic activity at $100 \mu \mathrm{M}$ (Figure S2C). Caffeic acid did not affect intracellular ATP levels in the differentiated SH-SY5Y cells, while hydrocaffeic acid (6.3 and $25 \mu \mathrm{M})$ and hydro-TriOH $(12.5 \mu \mathrm{M})$ increased ATP levels. By contrast, TriOH decreased ATP levels in the differentiated SH-SY5Y cells at $1 \mu \mathrm{M}$ and at concentrations higher than $25 \mu \mathrm{M}$ compared to the untreated cells (Figure S3C). Comparing MitoCINs with their respective parental compounds, we observed that $\mathrm{MC}_{3}, \mathrm{MC}_{6.2}$ and $\mathrm{MC}_{7.2}$ presented higher cytotoxicity than caffeic, hydrocaffeic acid and hydro TriOH, respectively, in both HepG2 and differentiated SH-SY5Y cells, while $\mathrm{MC}_{4}$ presented a similar cytotoxicity compared to the parental TriOH (Figures S4B,D, S5B,D and S6B,D).

Relative to the alkylTPP controls, both TPP-C8 and TPP-C10 reduced HepG2 cell mass (Figure S1B), metabolic activity (Figure S2B) and intracellular ATP levels (Figure S3B) at $1 \mu \mathrm{M}$. TPP-C6 at concentrations above $1 \mu \mathrm{M}$ decreased HepG2 cell mass (Figure S1B), metabolic activity (Figure S2B) and ATP levels (Figure S3B). The differentiated SH-SY5Y cells were less susceptible to the cytotoxicity of alkylTPP derivatives; TPP-C6 (25 $\mu \mathrm{M})$, TPPC8 $(25 \mu \mathrm{M})$ and TPP-C10 $(1 \mu \mathrm{M})$ reduced cell mass, while TPP-C6 (12.5 and $50 \mu \mathrm{M})$, TPP-C8 $(3.2$ and $50 \mu \mathrm{M})$ and TPP-C10 $(1 \mu \mathrm{M})$ treatment resulted in lower ATP levels (Figure S3D) and reduced metabolic activity (Figure S2D). In general, our results show that $\mathrm{MC}_{3}, \mathrm{MC}_{6.2}$, $\mathrm{MC}_{4}$ and $\mathrm{MC}_{7.2}$ presented lower cytotoxicity than TPP-C6, TPP-C8 and TPP-C10 in both HepG2 and differentiated SH-SY5Y cells (Figures S4B,D, S5B,D and S6B,D).

By analyzing the cytotoxic effects of the other type of mitochondria-targeted antioxidants, our results demonstrate that HepG2 cells treated with MitoQ and $\mathrm{SkQ}_{1}$ showed decreased cell mass (Figure 2B) and metabolic activity (Figure 3B) at concentrations above 3.2 $\mu \mathrm{M}$ compared to untreated cells. MitoQ and $\mathrm{SkQ}_{1}$ also decreased ATP levels of HepG2 cells at concentrations above 3.2 and $1 \mu \mathrm{M}$, respectively (Figure $4 \mathrm{~B}$ ). In the differentiated SH-SY5Y cells, MitoQ and $S k Q_{1}$ reduced cell mass (Figure 2D) and metabolic activity (Figure 3D) at concentrations above $3.2 \mu \mathrm{M}$. The differentiated SH-SY5Y cells treated with MitoQ and $\mathrm{SkQ}_{1}$ also presented lower ATP levels at concentrations above $1 \mu \mathrm{M}$ compared to untreated cells (Figure 4D).

Comparing the cytotoxic effect of $\mathrm{MC}_{3}$ with that of the two quinone-based mitochondrialtargeted antioxidants, we found a higher reduction of cell mass and intracellular ATP levels of HepG2 cells treated with MitoQ and $S_{k} Q_{1}$ relative to $M_{3}$ at concentrations above $1 \mu \mathrm{M}$ (Figures S4A and S6A). Additionally, the cells treated with MitoQ and SkQ 1 already showed decreased metabolic activity compared $\mathrm{MC}_{3}$ at $3.2 \mu \mathrm{M}$ (Figure S5A). A superior reduction in differentiated SH-SY5Y cell mass and metabolic activity was observed after MitoQ and $\mathrm{SkQ}_{1}$ treatment compared to $\mathrm{MC}_{3}$ above 3.2 and $6.3 \mu \mathrm{M}$, respectively (Figures S4C and S5C). The cells treated with MitoQ and $S_{k} Q_{1}$ at concentrations above $1 \mu \mathrm{M}$ showed a decrease of ATP values compared to cells treated with identical concentrations of $\mathrm{MC}_{3}$ (Figure S6C). These results suggest that $\mathrm{MC}_{3}$ presented lower cytotoxicity than mitochondrial-targeted antioxidants MitoQ, $\mathrm{SkQ}_{1}$ in HepG2 and SH-SY5Y cells.

Similarly to $\mathrm{MC}_{3}$, the cells treated with $\mathrm{MC}_{6.2}$ presented a lower reduction in cell mass, metabolic activity and intracellular ATP levels compared to MitoQ and $\mathrm{SkQ}_{1}$ at concentrations higher than $1 \mu \mathrm{M}$ (Figures S4A, S5A and S6A). The differentiated SH-SY5Y cells treated with MitoQ and $S k Q_{1}$ presented a significantly higher reduction of cell mass compared to $\mathrm{MC}_{6.2}$ at concentrations higher than 1 and $3.2 \mu \mathrm{M}$, respectively (Figure S4C). The cells treated with MitoQ and $\mathrm{SkQ}_{1}$ showed a higher loss of metabolic activity than $\mathrm{MC}_{6.2}$ at concentrations higher than 3.2 and $6.3 \mu \mathrm{M}$, respectively (Figure S5C). Additionally, the cells treated with MitoQ and $\mathrm{SkQ}_{1}$ at concentrations above $1 \mu \mathrm{M}$ showed lower ATP values compared to cells treated with identical concentrations of $\mathrm{MC}_{6.2}$ (Figure S6C). These results also suggest that $\mathrm{MC}_{6.2}$ is less toxic than the mitochondria-targeted antioxidants MitoQ and $S k Q_{1}$ in the two cell lines.

HepG2 cells treated with MitoQ and $\mathrm{SkQ}_{1}$ at concentrations above $1 \mu \mathrm{M}$ presented significantly lower cell mass, metabolic activity and intracellular ATP levels compared to identical concentrations of $\mathrm{MC}_{4}$ (Figures S4A, S5A and S6A). Similarly, a significantly superior reduction in cell mass occurred in the differentiated SH-SY5Y cells treated with 
MitoQ and $\mathrm{SkQ}_{1}$ compared to $\mathrm{MC}_{4}$ at concentrations higher than 1 and $3.2 \mu \mathrm{M}$, respectively (Figure S4C). In terms of metabolic activity, the cells treated with MitoQ and $S_{k} Q_{1}$ presented a superior reduction when compared to $\mathrm{MC}_{4}$ at concentrations higher than 3.2 and $6.3 \mu \mathrm{M}$ (Figure S5C). Additionally, the cells treated with MitoQ and $\mathrm{SkQ}_{1}$ at $1 \mu \mathrm{M}$ showed lower ATP values compared to cells treated with identical concentrations of $\mathrm{MC}_{4}$ (Figure S6C). Our results suggest that $\mathrm{MC}_{4}$ is less toxic than MitoQ and $\mathrm{SkQ}_{1}$ in HepG2 and SH-SY5Y cells.

Additionally, cells treated with concentrations above $1 \mu \mathrm{M}$ of MitoQ and $\mathrm{SkQ}_{1}$ also showed a superior reduction in cell mass, metabolic activity and intracellular ATP levels compared with identical concentrations of $\mathrm{MC}_{7.2}$ (Figures S4A, S5A and S6A). However, the differentiated SH-SY5Y cells treated with MitoQ and $\mathrm{SkQ}_{1}$ presented a superior reduction in their mass, compared to cells treated with $M_{7.2}$, at concentrations above 3.2 and $6.3 \mu \mathrm{M}$, respectively (Figure S4C). We found that the cells treated with MitoQ and SkQ also presented a superior reduction in metabolic activity compared to cells treated with $\mathrm{MC}_{7.2}$ at concentrations above $6.3 \mu \mathrm{M}$ (Figure S5C). Likewise, the cells treated with MitoQ and $\mathrm{SkQ}_{1}$ at $1 \mu \mathrm{M}$ showed lower ATP values compared to cells treated with identical concentrations of $\mathrm{MC}_{7.2}$ (Figure S6C). Together, these results suggest that $\mathrm{MC}_{7.2}$ presented lower cytotoxicity than mitochondria-targeted antioxidants MitoQ, SkQ 1 in HepG2 and differentiated SH-SY5Y cells.

Analyzing the cytotoxic effects of non-targeted resveratrol or $\mathrm{CoQ}_{10}$ in the HepG2 cells, our data showed that resveratrol increased the cell mass at concentrations of 1 and $3.25 \mu \mathrm{M}$, and decreased it at concentrations above $25 \mu \mathrm{M}$ compared to untreated cells (Figure $2 \mathrm{~B}$ ). On the other hand, $\mathrm{CoQ}_{10}$ did not affect the cell mass up to $100 \mu \mathrm{M}$ (Figure 2B). Our results also showed that resveratrol reduced HepG2 metabolic activity above $50 \mu \mathrm{M}$. The HepG2 cells treated with $\mathrm{CoQ}_{10}$ showed increased metabolic activity at 6.3 and $50 \mu \mathrm{M}$ compared to untreated cells (Figure 3B). On the other hand, the HepG2 cells treated with $\mathrm{CoQ}_{10}(25$ and $50 \mu \mathrm{M})$ and resveratrol $(25 \mu \mathrm{M})$ presented higher ATP levels (Figure 4B).

The loss of HepG2 cell mass that occurred with concentrations above 12.5 and $25 \mu \mathrm{M}$ $\mathrm{MC}_{3}$ was comparable to the effect of identical concentrations of $\mathrm{CoQ}_{10}$ and resveratrol, respectively (Figure S4A). The cells treated with $\mathrm{MC}_{3}$ above 25 and $50 \mu \mathrm{M}$ showed lower metabolic activity compared to similar concentrations of $\mathrm{CoQ}_{10}$ and resveratrol, respectively (Figure S5A). Additionally, cells treated with $\mathrm{MC}_{3}$ above 6.3 and $3.2 \mu \mathrm{M}$ showed lower intracellular ATP levels than with similar concentrations of $\mathrm{CoQ}_{10}$ and resveratrol (Figure S6A).

In differentiated SH-SY5Y cells, our results showed that resveratrol decreased cell mass at concentrations above $25 \mu \mathrm{M}$ compared to untreated cells, while $\mathrm{CoQ}_{10}$ did not affect cell mass up to $100 \mu \mathrm{M}$ (Figure 2D). Resveratrol and $\mathrm{CoQ}_{10}$ did not affect the metabolic activity relative to untreated cells (Figure $3 \mathrm{D}$ ). On the other hand, $\mathrm{CoQ}_{10}$ increased intracellular ATP levels in differentiated SH-SY5Y cells at concentrations of 1 and $3.2 \mu \mathrm{M}$. The differentiated SH-SY5Y cells treated with resveratrol showed increased intracellular ATP levels at $3.2 \mu \mathrm{M}$, and decreased levels at concentrations above $25 \mu \mathrm{M}$ compared to untreated cells (Figure 4D). Compared with the non-targeted antioxidants, $\mathrm{MC}_{3} 100 \mu \mathrm{M}$ resulted in a superior loss of cell mass to $100 \mu \mathrm{M} \mathrm{CoQ}_{10}$ (Figure S4C), without any difference in cell mass alterations between $\mathrm{MC}_{3}$ and resveratrol. No differences between $\mathrm{MC}_{3}, \mathrm{CoQ}_{10}$, or resveratrol were observed regarding metabolic activity (Figure S5C). The cells treated with $\mathrm{MC}_{3} 100 \mu \mathrm{M}$ presented lower intracellular ATP levels compared to cells treated with $100 \mu \mathrm{M} \mathrm{CoQ}_{10}$, while no alterations in intracellular ATP levels were observed when comparing cells treated with resveratrol and $\mathrm{MC}_{3}$ (Figure $\mathrm{S6C}$ ).

Regarding $\mathrm{MC}_{6.2}$, our results showed a superior loss of cell mass above 6.3 and $12.5 \mu \mathrm{M}$ compared to similar concentrations of $\mathrm{CoQ}_{10}$ and resveratrol, respectively (Figure S4A,C). As observed in cell mass assays, cells treated with concentrations above $12.5 \mu \mathrm{M} \mathrm{MC}_{6.2}$ showed reduced metabolic activity and intracellular ATP levels compared to identical concentrations of $\mathrm{CoQ}_{10}$ and resveratrol (Figures S5A,C and S6A,C). 
Additionally, no differences in cell mass and metabolic activity between $\mathrm{CoQ}_{10}$ and $\mathrm{MC}_{4}$ at concentrations up to $100 \mu \mathrm{M}$ were found. The cells treated with resveratrol at concentrations above $25 \mu \mathrm{M}$ presented a superior reduction in cell mass and metabolic activity compared to cells treated with identical concentrations of $\mathrm{MC}_{4}$ (Figures S4A and S5A). $\mathrm{MC}_{4}$ at concentrations up to $100 \mu \mathrm{M}$ did not differ from the same concentrations of $\mathrm{CoQ}_{10}$ and resveratrol regarding its effects on HepG2 ATP levels (Figure S6A).

No differences in the effects of $\mathrm{MC}_{4}$ and $\mathrm{CoQ}_{10}$ at concentrations up to $100 \mu \mathrm{M}$ on differentiated SH-SY5Y cell mass were observed. However, the cells treated with resveratrol at concentrations above $50 \mu \mathrm{M}$ presented a superior reduction in cell mass compared to $\mathrm{MC}_{4}$ (Figure $\mathrm{S4C}$ ). No differences in metabolic activity were observed when comparing the cells treated with $\mathrm{MC}_{4}$ and $\mathrm{CoQ}_{10}$ and resveratrol at concentrations up to $100 \mu \mathrm{M}$ (Figure S5C). Additionally, cells treated with $\mathrm{MC}_{4}$ presented lower intracellular ATP levels when compared to $\mathrm{CoQ}_{10}$ at $100 \mu \mathrm{M}$, while cells treated with resveratrol at concentrations above $50 \mu \mathrm{M}$ presented significantly lower intracellular ATP levels compared with identical concentrations of $\mathrm{MC}_{4}$ (Figure $\mathrm{S6C}$ ). Our results suggest that $\mathrm{MC}_{4}$ is less toxic than resveratrol in HepG2 and SH-SY5Y cells.

Similarly, by comparing the cytotoxic effect of $\mathrm{MC}_{7.2}$ with that of non-targeted antioxidants, our results showed that $\mathrm{MC}_{7.2}$ at $100 \mu \mathrm{M}$ led to a superior decrease in HepG2 cell mass compared to identical concentrations of $\mathrm{CoQ}_{10}$ (Figure S4A). By contrast, no differences in cell mass effects were observed when comparing cells treated with resveratrol and $\mathrm{MC}_{7.2}$ at concentrations up to $100 \mu \mathrm{M}$ (Figure S4A). Likewise, no alterations were observed in metabolic activity between cells treated with $\mathrm{MC}_{7.2}$ and $\mathrm{CoQ}_{10}$ or resveratrol at concentrations up to $100 \mu \mathrm{M}$ (Figure S5A). The cells treated with $\mathrm{MC}_{7.2}$ at 12.5 and $25 \mu \mathrm{M}$ presented lower intracellular ATP levels compared to cells treated with identical concentrations of $\mathrm{CoQ}_{10}$ and resveratrol, respectively (Figure S6A). No differences were observed in differentiated SH-SY5Y cell mass and metabolic activity after treatment with $\mathrm{CoQ}_{10}$ and resveratrol up to $100 \mu \mathrm{M}$. Additionally, $\mathrm{MC}_{7.2}$ resulted in a superior decrease in intracellular ATP levels at $100 \mu \mathrm{M}$ compared to cells treated with $\mathrm{CoQ}_{10}$ (Figure S6C). Additionally, the differentiated SH-SY5Y cells treated with $\mathrm{MC}_{7.2}$ at concentrations above $12.5 \mu \mathrm{M}$ presented lower ATP levels compared to cells treated with identical concentrations of resveratrol (Figure S6C). These data suggest that $\mathrm{MC}_{7.2}$ presented higher cytotoxicity than $\mathrm{CoQ}_{10}$ and resveratrol in these two cell lines.

\subsection{Comparative Effects of MitoCINs and Targeted-and Non-Targeted Antioxidants on Mitochondrial Membrane Potential and Cellular OCR/ECAR}

Based on the previous results obtained with the four MitoCINs and targeted-and non-targeted antioxidants, we selected the two highest concentrations that showed no cytotoxicity or a reduction in cytotoxicity of less than $40 \%$ compared to untreated cells. The concentrations selected were: $\mathrm{MC}_{3}: 12.5$ and $25 \mu \mathrm{M}$ for HepG2 and 25 and $50 \mu \mathrm{M}$ for differentiated SH-SY5Y; $\mathrm{MC}_{6.2}: 6.3$ and $12.5 \mu \mathrm{M}$ for HepG2 and 12.5 and $25 \mu \mathrm{M}$ for differentiated SH-SY5Y; MC 4 : 50 and $100 \mu \mathrm{M}$ for HepG2 and differentiated SH-SY5Y; $\mathrm{MC}_{7.2}: 50$ and $100 \mu \mathrm{M}$ for HepG2 and 25 and $50 \mu \mathrm{M}$ for differentiated SH-S cells; SkQ 10.5 and $1 \mu \mathrm{M}$ for HepG2 and 1.5 and $3.1 \mu \mathrm{M}$ for differentiated SH-SY5Y cells; CoQ ${ }_{10}: 50$ and $100 \mu \mathrm{M}$ for HepG2 and differentiated SH-SY5Y cells; resveratrol: 25 and $50 \mu \mathrm{M}$ for HepG2 and differentiated SH-SY5Y cells. The untreated cells, as well as non-cytotoxic concentrations of the parental or alkylTPP compounds, were also used as controls. Although the concentrations were different in several cases, our objective was to compare the mitochondrial effects of MitoCINs with the quinone-based mitochondria-targeted antioxidants and non-targeted antioxidants, at the highest non-toxic concentrations.

\subsubsection{Alterations in Mitochondrial Membrane Potential}

The comparison between the mitochondrial membrane potentials of the HepG2 and differentiated SH-SY5Y cells treated with the three classes of compounds was determined indirectly by measuring cellular TMRM fluorescence intensity. 
The selected concentrations of $\mathrm{MC}_{3}$ (up to $40 \%$ reduction in HepG2 cells, up to $20 \%$ reduction in differentiated SH-SY5Y cells), $\mathrm{MC}_{6.2}$ (up to $40 \%$ reduction in HepG2 cells, up to $25 \%$ reduction in differentiated SH-SY5Y cells), $\mathrm{MC}_{4}$ (no effect on HepG2, up to $20 \%$ reduction in differentiated SH-SY5Y cells) and $M_{7.2}$ (up to $40 \%$ reduction in HepG2 cells, up to $20 \%$ reduction in differentiated SH-SY5Y cells) significantly reduced the mitochondrial membrane potential compared to untreated HepG2 (Figure 5A) or the differentiated SH-SY5Y cells (Figure 5C). The next step was to compare the compounds of the MitoCIN library with the two other classes of compounds. Comparing $\mathrm{MC}_{3}$ with the other mitochondria-targeted antioxidants, our results showed that the non-cytotoxic concentrations of MitoQ $(0.1$ and $0.5 \mu \mathrm{M})$ significantly decreased the mitochondrial membrane potential in the HepG2 cells (Figure $5 \mathrm{~B}$ ), albeit by a lower degree compared to $\mathrm{MC}_{3}$ (25 $\mu \mathrm{M}$, Figure S7A). SkQ 1 (0.5 and $1 \mu \mathrm{M}$, Figure 5B) had no effect on HepG2 mitochondrial membrane potential. In differentiated SH-SY5Y cells, $\mathrm{SkQ}_{1}(1.5$ and $3.1 \mu \mathrm{M})$ significantly decreased the mitochondrial membrane potential compared to untreated cells (Figure 5D), again in a lower magnitude than $\mathrm{MC}_{3}(25$ and $50 \mu \mathrm{M}$, Figure S7D). Comparing the extent of the effects of $\mathrm{MC}_{6.2}(12.5 \mu \mathrm{M}$ for HepG2 and 12.5 and $25 \mu \mathrm{M}$ for differentiated SH-SY5Y cells) with the other mitochondrial-targeted antioxidants, our results showed that $\mathrm{SkQ}_{1}$ (0.5 and $1 \mu \mathrm{M}$ for HepG2 and 1.5 and $3.1 \mu \mathrm{M}$ for differentiated SH-SY5Y cells) significantly decreased mitochondrial membrane potential in HepG2 (Figure S7A) and differentiated SH-SY5Y cells to a lesser extent than $\mathrm{MC}_{6.2}$ (Figure S7D). We also observed that MitoQ (0.1 and $0.5 \mu \mathrm{M}$ ) reduced mitochondrial membrane potential in HepG2 cells to a lesser extent than $12.5 \mu \mathrm{M} \mathrm{MC}_{6.2}$ (Figure S7A). Similarly, in differentiated SH-SY5Y cells, $\mathrm{MC}_{6.2}(12.5$ and $25 \mu \mathrm{M})$ significantly decreased mitochondrial membrane potential to a greater extent than MitoQ (0.5 and $1.5 \mu \mathrm{M}$, Figure S7D).

Comparing $\mathrm{MC}_{4}$ with the quinone-based mitochondria-targeted antioxidants, we observed that $100 \mu \mathrm{M} \mathrm{MC}_{4}$ caused a significantly greater loss in mitochondrial membrane potential compared to MitoQ $(0.1$ and $0.5 \mu \mathrm{M})$ in HepG2 (Figure S7A) or to SkQ1 (1.5 and $3.1 \mu \mathrm{M}$ ) in the SH-SY5Y cells (Figure S7D). The HepG2 cells treated with 50 and $100 \mu \mathrm{M} \mathrm{MC}_{7.2}$ showed a significantly greater decrease in mitochondrial membrane potential compared to cells treated with MitoQ $(0.1$ and $0.5 \mu \mathrm{M})$ and $\mathrm{SkQ}_{1}(0.5$ and $1 \mu \mathrm{M})$ (Figure S7A). The differentiated SH-SY5Y cells treated with $50 \mu \mathrm{M} \mathrm{MC} 7.2$ presented lower mitochondrial membrane potential compared to the cells treated with MitoQ (0.5 and $1.5 \mu \mathrm{M})$, but without significant alterations compared to the cells treated with $S_{k} Q_{1}(0.5$ and $1 \mu \mathrm{M})$ (Figure S7D).

Comparing $\mathrm{MC}_{3}$ with the non-targeted antioxidants, our results showed that the noncytotoxic concentrations of resveratrol $(25$ and $50 \mu \mathrm{M}), \mathrm{CoQ}_{10}(50$ and $100 \mu \mathrm{M})$ significantly decreased mitochondrial membrane potential in HepG2 cells compared to untreated cells (Figure 5D), albeit with a lower magnitude when compared to $\mathrm{MC}_{3}(25 \mu \mathrm{M})$ (Figure S7A).

In the differentiated SH-SY5Y cells, resveratrol $(25$ and $50 \mu \mathrm{M})$ and $\mathrm{CoQ}_{10}(50$ and $100 \mu \mathrm{M})$ also significantly decreased mitochondrial membrane potential compared to untreated cells (Figure 5D), with a lower amplitude than $\mathrm{MC}_{3}(50 \mu \mathrm{M})$ (Figure S7D).

Comparing the extension of effects of $\mathrm{MC}_{6.2}(12.5 \mu \mathrm{M}$ for HepG2 and 12.5 and $25 \mu \mathrm{M}$ for differentiated SH-SY5Y cells) with those of the non-targeted antioxidants, our results showed that $\mathrm{CoQ}_{10}(50$ and $100 \mu \mathrm{M})$ and resveratrol $(25$ and $50 \mu \mathrm{M})$ significantly decreased mitochondrial membrane potential in HepG2 and differentiated SH-SY5Y cells, to a lesser extent than $\mathrm{MC}_{6.2}$ (Figure S7A,D).

Additionally, we observed that $100 \mu \mathrm{M} \mathrm{MC}$ caused a superior loss of mitochondrial membrane than resveratrol $(25$ and $50 \mu \mathrm{M})$ and $\mathrm{CoQ}_{10}(50$ and $100 \mu \mathrm{M})$ in the HepG2 cells (Figure S7A) or when compared to resveratrol $(25 \mu \mathrm{M})$ in the SH-SY5Y cells (Figure S7D). 

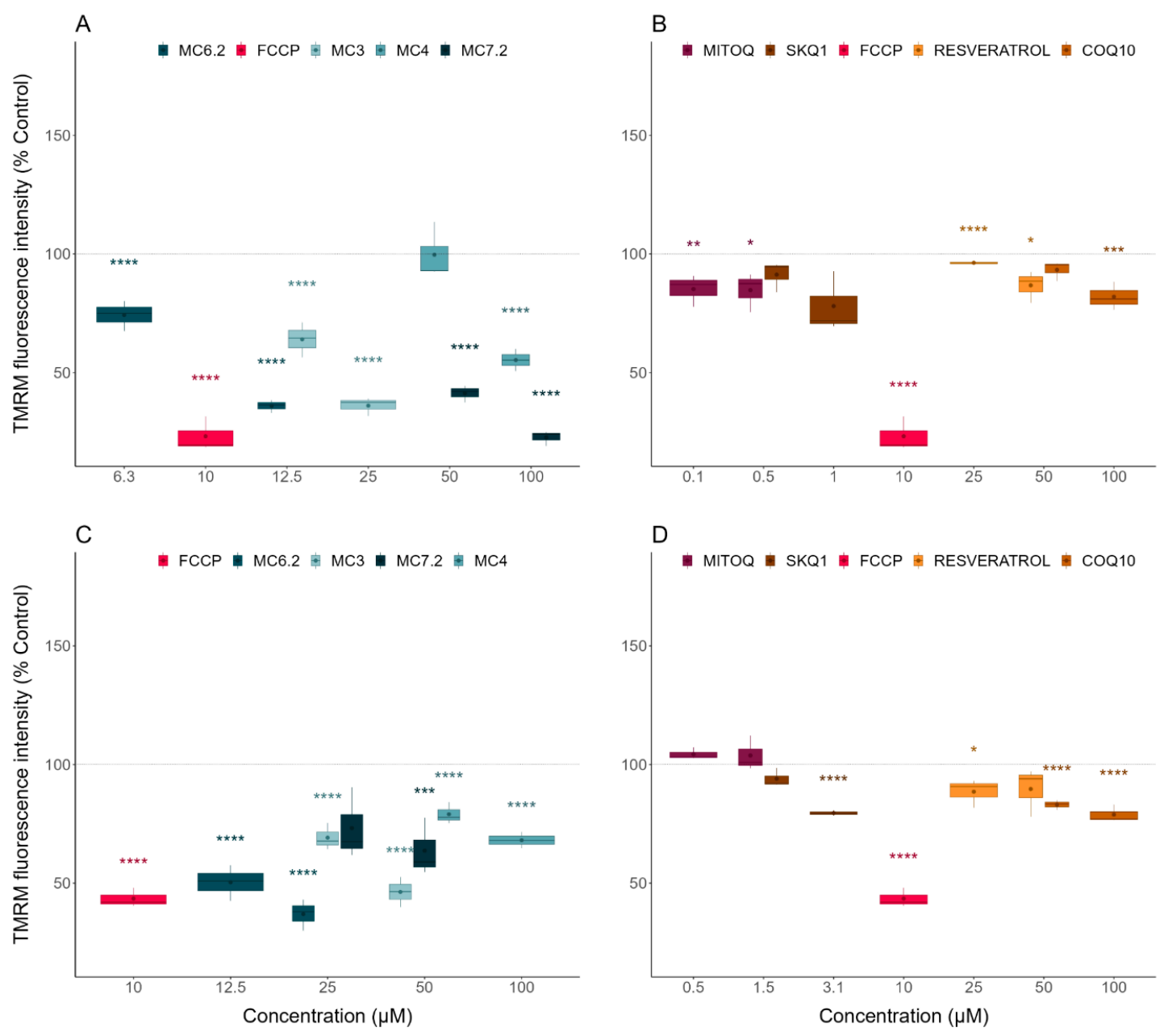

Figure 5. Effect of MitoCINs, quinone-based mitochondria-targeted and non-targeted antioxidants on TMRM intensity fluorescence. Human Caucasian hepatocyte carcinoma (HepG2, (A,B)) and differentiated human neuroblastoma (SH-SY5Y, $(C, D))$ were treated with increasing concentrations of the different molecules for a period of $48 \mathrm{~h}$ and mitochondrial membrane potential was indirectly evaluated using TMRM fluorescence intensity. Data are the mean \pm SE of three independent experiments and the results are expressed as percentage of the control (control $=100 \%$ ). Statistically significant differences between control (CTL) and treated groups were evaluated using a $t$-test. ${ }^{* * * *} p<0.0001,{ }^{* * *} p<0.001,{ }^{* *} p<0.01$ and ${ }^{*} p<0.05$ compared to the respective control (CTL).

The HepG2 cells treated with 50 and $100 \mu \mathrm{M} \mathrm{MC}_{7.2}$ presented reduced mitochondrial membrane potential compared to the cells treated with $\mathrm{CoQ}_{10}(50$ and $100 \mu \mathrm{M})$ and resveratrol $(25$ and $50 \mu \mathrm{M})$ (Figure S7A). No alterations were observed in the differentiated SH-SY5Y cells treated with 50 and $100 \mu \mathrm{M} \mathrm{MC}_{7.2}$, compared to the cells treated with $\mathrm{CoQ}_{10}(50$ and $100 \mu \mathrm{M})$ and resveratrol $(25$ and $50 \mu \mathrm{M})$ (Figure S7D), since these molecules decreased the mitochondrial membrane potential per se. Overall, the four MitoCINs significantly decreased the mitochondrial membrane potential to a greater extent than $\mathrm{CoQ}_{10}$, resveratrol, MitoQ and $\mathrm{KkQ}_{1}$.

The mitochondrial membrane potential of HepG2 and differentiated SH-SY5Y cells treated with MitoCINs parental compounds and their alkylTPP constituents were also measured to gain insights into cytotoxicity mechanisms. No alterations in mitochondrial membrane potential were observed in HepG2 cells treated with caffeic acid $(50 \mu \mathrm{M})$, hydrocaffeic acid $(100 \mu \mathrm{M}), \mathrm{TriOH}(50$ and $100 \mu \mathrm{M})$ and hydro-TriOH $(50$ and $100 \mu \mathrm{M})$. However, the HepG2 cells treated with $50 \mu \mathrm{M}$ hydrocaffeic acid showed increased mitochondrial membrane potential, while $100 \mu \mathrm{M}$ caffeic acid reduced this parameter in the HepG2 cells (Figure S8A). In differentiated SH-SY5Y cells, caffeic acid (50 and $100 \mu \mathrm{M})$, TriOH (50 and $100 \mu \mathrm{M})$ and hydro-TriOH $(50 \mu \mathrm{M})$ did not have any effect on mitochondrial mem- 
brane potential. As in the assays on HepG2 cells, differentiated SH-SY5Y cells treated with $50 \mu \mathrm{M}$ hydrocaffeic acid showed an increase in mitochondrial membrane potential. On the other hand, differentiated SH-SY5Y cells treated with $100 \mu \mathrm{M}$ hydrocaffeic acid or hydroTriOH presented reduced mitochondrial membrane potential compared to untreated cells (Figure S8C). In sum, our results showed that $\mathrm{MC}_{3}, \mathrm{MC}_{6.2}$ and $\mathrm{MC}_{4}$ reduced mitochondrial membrane potential compared to their parental compounds in both cell lines (Figure S7B,E). $\mathrm{MC}_{7.2}$ also reduced mitochondrial membrane potential compared to hydrocaffeic acid in HepG2 cells, without showing any alterations in the differentiated SH-SY5Y cells (Figure S7B,E).

Considering the alkylTPP compounds, no alterations in mitochondrial membrane potential were observed in HepG2 (Figure S4B) and differentiated SH-SY5Y cells (Figure S4D) treated with TPP-C6 $(0.5$ and $1 \mu \mathrm{M}$ for HepG2 and 3.1 and $6.25 \mu \mathrm{M}$ for differentiated SH-SY5Y cells), TPP-C8 (0.5 and $1 \mu \mathrm{M}$ for HepG2 and 3.1 and $6.25 \mu \mathrm{M}$ for differentiated SH-SY5Y cells) and TPP-C10 $(0.1 \mu \mathrm{M}$ for HepG2 and $1.5 \mu \mathrm{M}$ for differentiated SHSY5Y cells) compared to untreated cells. However, HepG2 cells treated with $0.01 \mu \mathrm{M}$ TPP-C10 presented reduced mitochondrial membrane potential compared to untreated cells (Figure S4B), while the differentiated SH-SY5Y cells treated with $0.5 \mu \mathrm{M}$ TPP-C10 showed an increase in mitochondrial membrane potential compared to untreated cells (Figure S4D). Comparing MitoCINs with their respective TPP cations, $\mathrm{MC}_{3}, \mathrm{MC}_{6.2}$, and $\mathrm{MC}_{7.2}$ reduced mitochondrial membrane potential in both cell lines (Figure S7C,F). However, $\mathrm{MC}_{4}$ only reduced mitochondrial membrane potential compared to TPP-C6 in the HepG2 cells (Figure S7C).

In sum, the MitoCINs significantly reduced mitochondrial membrane potential compared to their respective parental compounds and TPP cations in the HepG2 and differentiated SH-SY5Y cells (except for differentiated SH-SY5Y cells treated with $\mathrm{MC}_{4}$ ). They also reduced mitochondrial membrane potential to a greater extent than the non-targeted and quinone-based mitochondrial-targeted antioxidants at the highest non-cytotoxic concentrations. Table 1 shows a summary of the mitochondrial membrane potential results.

Table 1. Comparison of cytotoxicity and mitochondrial effects of MitoCIN compounds in HepG2 and differentiated SH-SY5Y cells.

\begin{tabular}{|c|c|c|}
\hline Assay & Key Finding & Potency/Effect Size \\
\hline Sulforhodamine B & Cell mass/Cytotoxicity & $\begin{array}{l}\text { HepG2: } \mathrm{MC}_{4}<\mathrm{MC}_{7.2}<\mathrm{MC}_{3}<\mathrm{MC}_{6.2} \\
\text { SH-SY5Y: } \mathrm{MC}_{4} \approx \mathrm{MC}_{7.2}<\mathrm{MC}_{3}<\mathrm{MC}_{6.2}\end{array}$ \\
\hline Resazurin & Cell metabolic activity/Cytotoxicity & $\begin{array}{l}\text { HepG2: } \mathrm{MC}_{4}<\mathrm{MC}_{7.2}<\mathrm{MC}_{3}<\mathrm{MC}_{6.2} \\
\text { SH-SY5Y: } \mathrm{MC}_{4} \approx \mathrm{MC}_{7.2}<\mathrm{MC}_{3}<\mathrm{MC}_{6.2}\end{array}$ \\
\hline Intracellular ATP levels & Cytotoxicity & $\begin{array}{l}\text { HepG2: } \mathrm{MC}_{4}=\mathrm{MC}_{7.2}<\mathrm{MC}_{3} \approx \mathrm{MC}_{6.2} \\
\text { SH-SY5Y: } \mathrm{MC}_{4}<\mathrm{MC}_{7.2} \approx \mathrm{MC}_{3}<\mathrm{MC}_{6.2}\end{array}$ \\
\hline TMRM & Mitochondrial polarization & $\begin{array}{l}\text { HepG2: } \mathrm{MC}_{4}<\mathrm{MC}_{6.2} \approx \mathrm{MC}_{3}<\mathrm{MC}_{7.2} \\
\text { SH-SY5Y: } \mathrm{MC}_{4} \approx \mathrm{MC}_{7.2}<\mathrm{MC}_{3}<\mathrm{MC}_{6.2}\end{array}$ \\
\hline Cellular OCR/ECAR & $\begin{array}{c}\text { Cellular respiration and indirect measurement } \\
\text { of cellular glycolytic activity }\end{array}$ & $\begin{array}{l}\text { HepG2: } \mathrm{MC}_{4} \approx \mathrm{MC}_{7.2} \approx \mathrm{MC}_{3} \approx \mathrm{MC}_{6.2} \\
\text { SH-SY5Y: } \mathrm{MC}_{4}<\mathrm{MC}_{7.2}<\mathrm{MC}_{3}<\mathrm{MC}_{6.2}\end{array}$ \\
\hline
\end{tabular}

TMRM: tetramethylrhodamine methyl ester, OCR: oxygen consumption rate, ECAR: extracellular acidification rate.

\subsubsection{Alterations in Cellular OCR and ECAR}

The evaluation of the cytotoxicity of the different MitoCINs and the non-targeted and quinone-based mitochondria-targeted antioxidants on the OCR and ECAR of the HepG2 and differentiated SH-SY5Y cells was performed by using an Agilent-Seahorse XFe96 analyzer.

$\mathrm{MC}_{3}(12.5$ and $25 \mu \mathrm{M}), \mathrm{MC}_{6.2}(6.3$ and $12.5 \mu \mathrm{M}), \mathrm{MC}_{4}(50$ and $100 \mu \mathrm{M})$ and $\mathrm{MC}_{7.2}$ (50 and $100 \mu \mathrm{M}$ ) did not induce any alterations in the OCR and ECAR parameters in the HepG2 cells (Figure 6A-K). Similarly, no differences were found in the OCR and ECAR parameters in the differentiated SH-SY5Y cells treated with $\mathrm{MC}_{3}(25$ and $50 \mu \mathrm{M})$ compared to untreated cells (Figure 7A-K). We observed that in these cells, $25 \mu \mathrm{M} \mathrm{MC}_{6.2}$ reduced the 
ATP production-linked OCR, proton leak-associated OCR, basal, maximal, and stressed OCR and increased the basal ECAR (Figure $7 \mathrm{~A}-\mathrm{K}$ ). On the other hand, $50 \mu \mathrm{M}$ of $\mathrm{MC}_{4}$ increased the ATP production-linked OCR, proton leak-associated OCR, non-mitochondrial respiration, basal and stressed OCR in the differentiated SH-SY5Y cells. $\mathrm{MC}_{4}(100 \mu \mathrm{M})$ also increased non-mitochondrial respiration (Figure $7 \mathrm{~A}-\mathrm{K})$. For $\mathrm{MC}_{7.2}(50 \mu \mathrm{M})$ our results showed an increase in proton leak and non-mitochondrial respiration (Figure 7A-K).

By analyzing the OCR and ECAR parameters of the two mitochondria-targeted antioxidants in clinical trials, our results showed that HepG2 cells treated with MitoQ (0.5 and $1 \mu \mathrm{M})$ and $\mathrm{SkQ}_{1}(0.5$ and $3 \mu \mathrm{M})$ did not show any alterations in their endpoints compared to untreated cells (Figure 6L-V) or with cells treated with $\mathrm{MC}_{3}(12.5$ and $25 \mu \mathrm{M})$ (Figure S9A-K).

When comparing the effects on differentiated SH-SY5Y cells, we observed that $\mathrm{MC}_{3}$ $50 \mu \mathrm{M}$ presented lower values of ATP production-linked OCR, proton leak-associated OCR, basal, non-mitochondrial, maximal and stressed OCR compared to the cells treated with MitoQ (0.5 and $1 \mu \mathrm{M})$ (Figure S10A-K). The cells treated with $50 \mu \mathrm{M} \mathrm{MC}$ also presented lower spare respiratory capacity than the cells treated with MitoQ (0.5 and $1 \mu \mathrm{M}$ ) (Figure S9H). The cells treated with $1.5 \mu \mathrm{M} \mathrm{SkQ}_{1}$ presented higher spare respiratory capacity than cells treated with $50 \mu \mathrm{M} \mathrm{MC}_{3}$, while cells treated with $3 \mu \mathrm{M} \mathrm{SkQ}_{1}$ presented higher spare respiratory capacity and maximal and stressed OCR, compared to the cells treated with $50 \mu \mathrm{M} \mathrm{MC}$ (Figure S10A-K).

No differences were observed in OCR and ECAR between HepG2 cells treated with $\mathrm{MC}_{6.2}(12.5$ and $25 \mu \mathrm{M})$ and MitoQ $(0.5$ and $1 \mu \mathrm{M})$ (Figure S9A-K). However, cells treated with $1 \mu \mathrm{M} \mathrm{SkQ}_{1}$ presented lower proton leak-associated OCR values than the HepG2 cells treated with $12.5 \mu \mathrm{M} \mathrm{MC}_{6.2}$ (Figure S9E). On the other hand, the differentiated SH-SY5Y cells treated with $25 \mu \mathrm{M} \mathrm{MC}_{6.2}$ presented lower ATP production-linked OCR, proton leakassociated OCR, basal, maximal, non-mitochondrial and stressed OCR compared to the cells treated with MitoQ $(0.5$ and $1 \mu \mathrm{M})$ and $\mathrm{SkQ}_{1}(1.5$ and $3 \mu \mathrm{M})$ (Figure S10A-K). The cells treated with MitoQ $(0.5$ and $1 \mu \mathrm{M})$ and $3 \mu \mathrm{M} \mathrm{SkQ}$ showed lower basal ECAR values than cells treated with $25 \mu \mathrm{M} \mathrm{MC}_{6.2}$ (Figure S10I). The spare respiratory capacity was also decreased in differentiated SH-SY5Y cells treated with $25 \mu \mathrm{M} \mathrm{MC}_{6.2}$ compared to cells treated with MitoQ $(0.5$ and $1 \mu \mathrm{M})$ and $\mathrm{SkQ}_{1}(1.5$ and $3 \mu \mathrm{M})$ (Figure $\left.\mathrm{S} 10 \mathrm{H}\right)$. Comparing $\mathrm{MC}_{4}$ with mitochondria-targeted antioxidants, no differences were observed when comparing HepG2 cells treated with $\mathrm{MC}_{4}(50$ and $100 \mu \mathrm{M})$, MitoQ $(0.1$ and $0.5 \mu \mathrm{M}$ for HepG2 and 0.5 and $1 \mu \mathrm{M}$ for differentiated SH-SY5Y cells) and $\mathrm{SkQ}_{1}(0.5$ and $1 \mu \mathrm{M}$ for HepG2 and 1.5 and $3 \mu \mathrm{M}$ for differentiated SH-SY5Y cells) (Figures S9 and S10). On the other hand, HepG2 cells treated with $\mathrm{MC}_{7.2}(50$ and $100 \mu \mathrm{M})$ presented similar values of OCR and ECAR compared to cells treated with MitoQ $(0.1$ and $0.5 \mu \mathrm{M})$ and $0.5 \mu \mathrm{M} \mathrm{SkQ}$ (Figure S9A-K). The cells treated with $25 \mu \mathrm{M} \mathrm{MC} 7.2$ also presented a significant reduction in non-mitochondrial respiration compared to cells treated with 0.5 and $1 \mu \mathrm{M}$ MitoQ (Figure S10G). In sum, $\mathrm{MC}_{3}$ and $\mathrm{MC}_{6.2}$ lowered ATP production-linked OCR, proton leak-associated OCR, basal, maximal and stressed OCR compared with MitoQ and SkQ1, while no alterations in any parameter were observed in HepG2 and differentiated SH-SY5Y cells treated with MC and $\mathrm{MC}_{7.2}$ or MitoQ and $\mathrm{SkQ}_{1}$.

The HepG2 cells treated with resveratrol $(25$ and $50 \mu \mathrm{M})$ and $\mathrm{CoQ}_{10}(50$ and $100 \mu \mathrm{M})$ did not show any differences in OCR and ECAR parameters compared to untreated cells (Figure 6L-V) or with the cells treated with $\mathrm{MC}_{3}(12.5$ and $25 \mu \mathrm{M})$ (Figure S9L-V). The differentiated SH-SY5Y cells treated with $50 \mu \mathrm{M} \mathrm{MC} 3$ presented lower values of ATP production-linked OCR, proton leak-associated OCR, basal, non-mitochondrial, maximal and stressed OCR compared to the cells treated with resveratrol $(25$ and $50 \mu \mathrm{M})$ and $\operatorname{CoQ}_{10}$ (50 and $100 \mu \mathrm{M})$ (Figure S10L-V). 

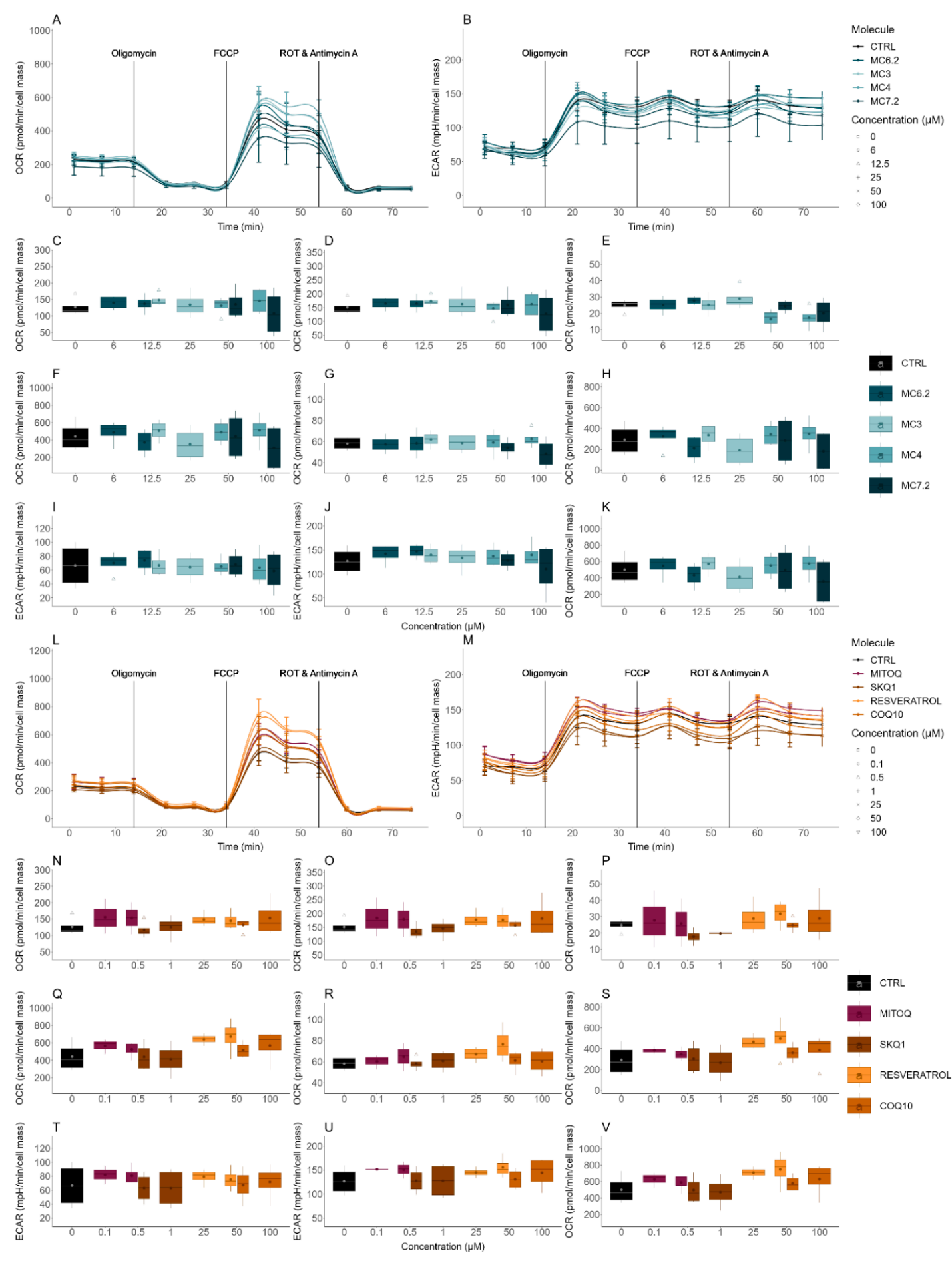

Figure 6. Effect of MitoCINs, quinone-based mitochondria-targeted and non-targeted antioxidants on oxygen consumption rate (OCR) and extracellular acidification rate (ECAR). OCR- and ECAR-associated parameters were assessed with a Seahorse XFe96 Extracellular Flux Analyzer. OCR (A,L) and ECAR (B,M) were assessed in human Caucasian hepatocyte carcinoma (HepG2) cells treated with increasing concentrations of the different molecules for a period of $48 \mathrm{~h}$. Several OCR parameters were evaluated: ATP production-linked OCR $(\mathbf{C}, \mathbf{N})$, basal respiration $(\mathbf{D}, \mathbf{O})$, proton leak-based OCR $(\mathbf{E}, \mathbf{P})$, maximal respiration $(\mathbf{F}, \mathbf{Q})$, non-mitochondrial respiration $(\mathbf{G}, \mathbf{R})$ and spare respiratory capacity $(\mathbf{H}, \mathbf{S})$. ECAR parameters were also evaluated, including basal ECAR $(\mathbf{I}, \mathbf{T})$, stressed ECAR $(\mathbf{J}, \mathbf{U})$ and stressed OCR $(\mathbf{K}, \mathbf{V})$. Data are the mean \pm SE of four independent experiments and the results are expressed in the interquartile range (Q1-Q3) together with the (-) median. Statistically significant differences between control (CTL) and treated groups were evaluated using a $t$-test. Significance was accepted with $p<0.05$. 

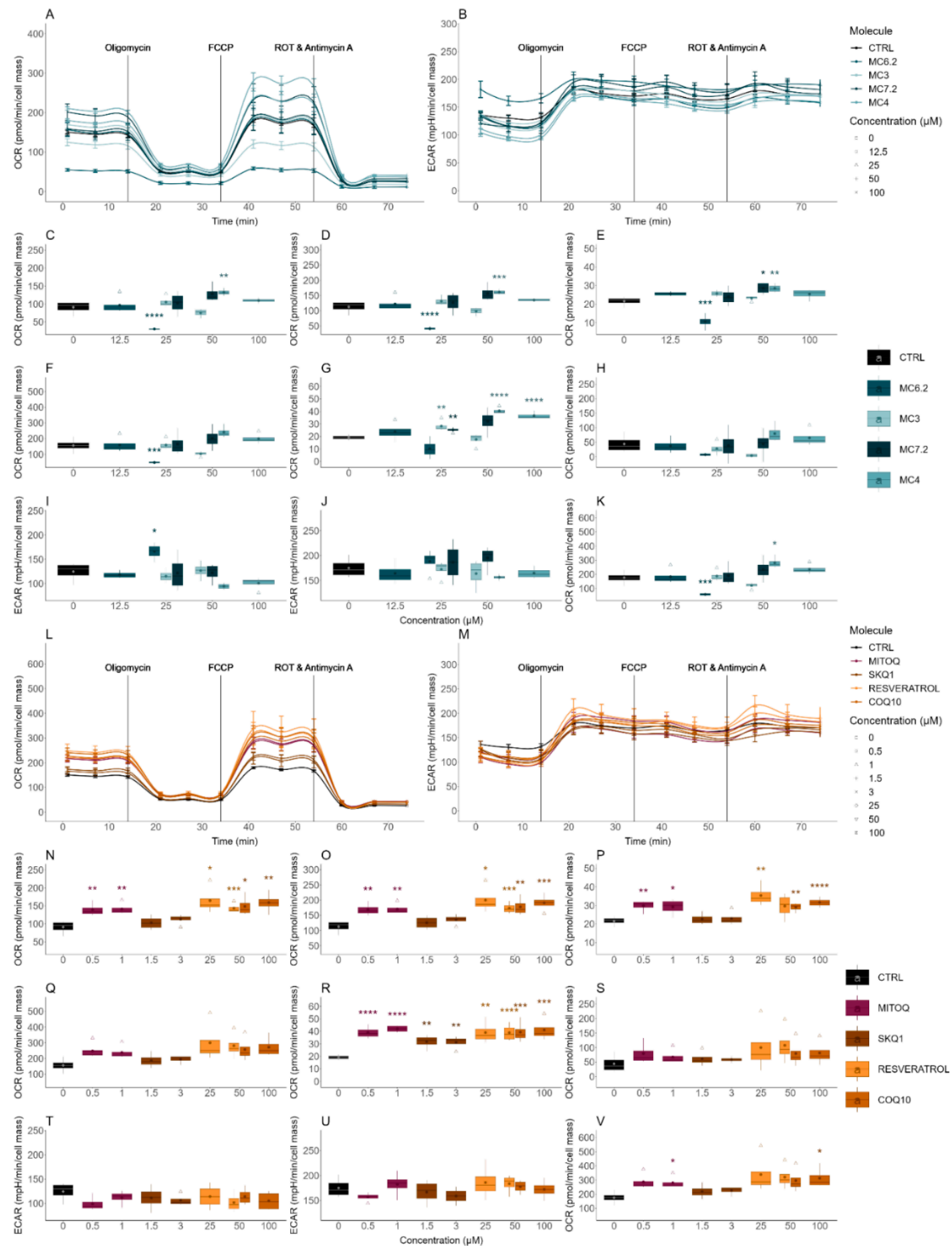

Figure 7. Effect of MitoCINs, quinone-based mitochondria-targeted and non-targeted antioxidants on oxygen consumption rate (OCR) and extracellular acidification rate (ECAR). OCR- and ECAR-associated parameters were assessed with a Seahorse XFe96 Extracellular Flux Analyzer. OCR (A,L) and ECAR (B,M) were assessed in differentiated human neuroblastoma (SH-SY5Y) cells treated with increasing concentrations of the different molecules for a period of $48 \mathrm{~h}$. Several OCR parameters were evaluated: ATP production-linked OCR $(\mathbf{C}, \mathbf{N})$, basal respiration $(\mathbf{D}, \mathbf{O})$, proton leak-based OCR $(\mathbf{E}, \mathbf{P})$, maximal respiration $(\mathbf{F}, \mathbf{Q})$, non-mitochondrial respiration $(\mathbf{G}, \mathbf{R})$ and spare respiratory capacity $(\mathbf{H}, \mathbf{S})$. ECAR parameters were also evaluated, including basal ECAR $(\mathbf{I}, \mathbf{T})$, stressed ECAR $(\mathbf{J}, \mathbf{U})$ and stressed OCR $(\mathbf{K}, \mathbf{V})$. Data are the mean \pm SE of four independent experiments and the results are expressed in the interquartile range (Q1-Q3) together with the (-) median. Statistically significant differences between control (CTL) and treated groups were evaluated using a $t$-test. ${ }^{* * * *} p<0.0001$, *** $p<0.001,{ }^{* *} p<0.01$ and ${ }^{*} p<0.05$ compared to the respective control (CTL). 
In HepG2 cells, no differences were observed between $\mathrm{MC}_{6.2}(12.5$ and $25 \mu \mathrm{M})$, resveratrol $(25$ and $50 \mu \mathrm{M})$ and $\mathrm{CoQ}_{10}(50$ and $100 \mu \mathrm{M})$. The differentiated SH-SY5Y cells treated with $25 \mu \mathrm{M} \mathrm{MC}_{6.2}$ presented reduced ATP production-linked OCR, proton leak-associated OCR, basal, maximal, non-mitochondrial and stressed OCR compared to the cells treated with resveratrol $(25$ and $50 \mu \mathrm{M})$ and $\mathrm{CoQ}_{10}(50$ and $100 \mu \mathrm{M})$ (Figure S10L-V). Interestingly, differentiated SH-SY5Y cells treated with $25 \mu \mathrm{M} \mathrm{MC}_{6.2}$ also showed higher basal ECAR values compared to those treated with resveratrol $(50 \mu \mathrm{M})$ and $\mathrm{CoQ}_{10}(50$ and $100 \mu \mathrm{M})$ (Figure S10T).

No differences were observed in OCR and ECAR when comparing HepG2 cells treated with $\mathrm{MC}_{4}(50$ and $100 \mu \mathrm{M})$, resveratrol $(25$ and $50 \mu \mathrm{M})$ or $\mathrm{CoQ}_{10}(50$ and $100 \mu \mathrm{M})$ (Figure S9L-V). However, differentiated SH-SY5Y cells treated with $100 \mu \mathrm{M} \mathrm{MC}_{4}$ presented lower basal respiration compared to cells treated with $50 \mu \mathrm{M}$ resveratrol and $100 \mu \mathrm{M} \mathrm{CoQ}_{10}$ (Figure S10O).

The HepG2 cells treated with $\mathrm{MC}_{7.2}(50$ and $100 \mu \mathrm{M})$ presented similar OCR and ECAR values compared to the cells treated with resveratrol (25 and $50 \mu \mathrm{M})$ and $\operatorname{CoQ}_{10}$ (50 and 100) (Figure S9L-V). The differentiated SH-SY5Y cells treated with $25 \mu \mathrm{M} \mathrm{MC} \mathrm{C}_{7.2}$ also presented a significant reduction in non-mitochondrial respiration compared to the cells treated with $50 \mu \mathrm{M}$ resveratrol (Figure S10R). Our results suggest that HepG2 cells treated with these four MitoCINs presented similar OCR and ECAR values compared to the cells treated with resveratrol and $\mathrm{CoQ}_{10}$. In differentiated SH-SY5Y cells, $\mathrm{MC}_{3}$ and $\mathrm{MC}_{6.2}$ reduced ATP production-linked OCR, proton leak-associated OCR, basal, maximal and stressed OCR compared to resveratrol and $\mathrm{CoQ}_{10}$.

The OCR and ECAR parameters of HepG2 and differentiated SH-SY5Y cells treated with parental compounds of all four MitoCINs and their alkylTPP constituents were also measured to gain insight into the cytotoxicity mechanisms of the MitoCIN compounds.

No differences in OCR and ECAR parameters were observed in HepG2 cells treated with caffeic acid (50 and $100 \mu \mathrm{M})$, hydrocaffeic acid (50 and $100 \mu \mathrm{M})$, TriOH $(50 \mu \mathrm{M})$ and hydro.Tri-OH (50 and $100 \mu \mathrm{M}$ ) (Figure S11A-K). However, $100 \mu \mathrm{M}$ TriOH decreased proton leak-associated OCR in HepG2 cells compared to untreated cells (Figure S11A-K). In differentiated SH-SY5Y cells, $50 \mu \mathrm{M}$ caffeic acid increased the ATP production-linked OCR, proton leak-associated OCR, basal, non-mitochondrial, maximal and stressed OCR, while $100 \mu \mathrm{M}$ caffeic acid increased the proton leak-associated OCR and non-mitochondrial OCR (Figure S12A-K). Our results also showed that hydrocaffeic acid (50 and $100 \mu \mathrm{M}$ ) increased the ATP production-linked, proton leak-associated OCR, basal, maximal, nonmitochondrial and stressed OCR compared to untreated cells (Figure S12A-K). TriOH (25 and $50 \mu \mathrm{M}$ ) increased the non-mitochondrial respiration compared to untreated cells (Figure S12A-K). The differentiated SH-SY5Y cells treated with $50 \mu \mathrm{M}$ hydro-TriOH increased the ATP production-linked OCR and proton leak-associated OCR compared to untreated cells. In comparison, $100 \mu \mathrm{M}$ hydro-TriOH increased the ATP productionlinked OCR, basal, proton leak-associated OCR, non-mitochondrial respiration, maximal and stressed OCR compared to untreated cells, without affecting the spare respiratory capacity (Figure S12A-K). No differences in these parameters were observed between HepG2 cells treated with $\mathrm{MC}_{3}(12.5$ and $25 \mu \mathrm{M}), \mathrm{MC}_{6.2}(6.3$ and $12.5 \mu \mathrm{M}), \mathrm{MC}_{4}(50$ and $100 \mu \mathrm{M})$ and $\mathrm{MC}_{7.2}(50$ and $100 \mu \mathrm{M})$ compared to their respective parental compounds (Figure S13A-K). In differentiated SH-SY5Y cells, $\mathrm{MC}_{3}\left(25\right.$ and $50 \mu \mathrm{M}$ ) and $\mathrm{MC}_{6.2}$ $(25 \mu \mathrm{M})$ presented lower ATP production-linked OCR, proton leak-associated OCR, basal, non-mitochondrial and stressed OCR compared to cells treated with their respective parental compounds (Figure S14A-K), while $\mathrm{MC}_{4}(50$ and $100 \mu \mathrm{M})$ and $\mathrm{MC}_{7.2}(25$ and $50 \mu \mathrm{M})$ presented similar OCR and ECAR parameters relative to their parental compounds (Figure S14L-V).

Considering alkylTPP compounds, no differences were measured between OCR and ECAR parameters in HepG2 cells treated with TPP-C6 $(0.5$ and $1 \mu \mathrm{M})$, TPP-C8 $(0.5$ and $1 \mu \mathrm{M})$ and TPP-C10 $(0.01$ and $0.1 \mu \mathrm{M})$ compared to untreated cells (Figure S11L-M). The differentiated SH-SY5Y cells treated with $3 \mu \mathrm{M}$ TPP-C6 presented a significant reduction 
in proton leak-associated OCR, while $6 \mu \mathrm{M}$ TPP-C6 reduced ATP production-linked, proton leak-associated OCR, basal, maximal, non-mitochondrial and stressed OCR and also increased the basal ECAR compared to untreated cells (Figure S12L-M). The differentiated SH-SY5Y cells treated with $6 \mu \mathrm{M}$ TPP-C8 presented reduced ATP production-linked OCR, proton leak-associated OCR, basal, non-mitochondrial, maximal and stressed OCR compared to untreated cells, as well as an increase in basal ECAR compared with the untreated cells (Figure S12L-M). On the other hand, $1 \mu \mathrm{M}$ TPP-C10 also decreased the ATP production-linked OCR, proton leak-associated OCR, basal, maximal, and stressed OCR compared to untreated cells (Figure S12L-M). In HepG2 cells, no differences in OCR and ECAR parameters were found between the cells treated with $\mathrm{MC}_{3}(12.5$ and $25 \mu \mathrm{M})$, $\mathrm{MC}_{6.2}(6.3$ and $12.5 \mu \mathrm{M}), \mathrm{MC}_{4}(50$ and $100 \mu \mathrm{M})$ and $\mathrm{MC}_{7.2}(50$ and $100 \mu \mathrm{M})$ and their respective alkylTPP cations (Figure S15A-K). Interestingly, the differentiated SH-SY5Y cells treated with $\mathrm{MC}_{3}(25$ and $50 \mu \mathrm{M}), \mathrm{MC}_{6.2}(25 \mu \mathrm{M}), \mathrm{MC}_{4}(50$ and $100 \mu \mathrm{M})$ and $\mathrm{MC}_{7.2}(50 \mu \mathrm{M})$ presented higher ATP production-linked OCR, proton leak-associated OCR, basal OCR compared to the cells treated with their respective TPP cations (Figure S16A-K).

In sum, $\mathrm{MC}_{3}$ and $\mathrm{MC}_{6.2}$ affected mitochondrial function in the HepG2 and differentiated SH-SY5Y cells more significantly than the non-targeted and quinone-based mitochondrial-targeted antioxidants $\left(\mathrm{MC}_{3}: 12.5-50 \mu \mathrm{M}\right.$ and $\mathrm{MC}_{6.2}: 6.3-25 \mu \mathrm{M}$ vs. SkQ1: 0.5-3.1 $\mu \mathrm{M}$ and MitoQ: 0.5-1 $\mu \mathrm{M}$ ), while $\mathrm{MC}_{4}$ and $\mathrm{MC}_{7.2}$ presented similar effects on mitochondrial function in both cell lines compared to the non-targeted and mitochondrialtargeted antioxidants $\left(\mathrm{MC}_{4}: 50-100 \mu \mathrm{M}\right.$ and $\mathrm{MC}_{7.2}: 25-100 \mu \mathrm{M}$ vs. SkQ1: 0.5-3.1 $\mu \mathrm{M}$, MitoQ: $0.5-1 \mu \mathrm{M}$, resveratrol: $25-50 \mu \mathrm{M}$ and $\mathrm{CoQ}_{10}$ : 50-100 $\left.\mu \mathrm{M}\right)$.

\section{Discussion}

The prevention of mitochondrial oxidative damage is a promising pharmacological strategy to delay the progression of oxidative stress-related diseases [1,35]. Based on this approach, targeting mitochondria with molecules functionalized with a $\mathrm{TPP}^{+}$moiety is a useful strategy for targeting different antioxidants inside the organelle [1,50]. Despite the relevance of mitochondrial-targeting drugs, several cytotoxic effects have been reported for a variety of systems, mostly related to ROS overproduction, membrane disruption and mitochondrial depolarization [5].

The $\mathrm{TPP}^{+}$-based mitochondria-targeted antioxidants MitoQ and $\mathrm{SkQ}_{1}$, based on coenzyme $\mathrm{Q}$ and plastoquinone moieties, respectively, both covalently linked to $\mathrm{TPP}^{+}-\mathrm{C} 10$, are two of the most commonly studied mitochondria-targeted antioxidants. Despite positive results in preclinical stages, both molecules present toxicity concerns, which are mainly related to the presence in the structure of a prooxidant quinone core [51-53]. As an alternative to MitoQ and $S k Q_{1}$, a library of antioxidants based on HCAs and analogs linked to alkyl TPP ${ }^{+}$was developed [23-25]. By extending our previous studies of this type of compound, our objective was to evaluate the cytotoxicity and effects on mitochondrial function of selected $\mathrm{TPP}^{+}$-based antioxidants from the MitoCINs library $\left(\mathrm{MC}_{3}, \mathrm{MC}_{6.2}, \mathrm{MC}_{4}\right.$ and $\mathrm{MC}_{7.2}$ ) and compare them with the outline obtained under the same experimental conditions for MitoQ and $S_{k} Q_{1}$ and with two non-targeted antioxidants that have been under clinical trials, resveratrol and $\mathrm{CoQ}_{10}$. We used HepG2 and differentiated SH-SY5Y cells as cell models for this study, since they are often used in preclinical safety assessment of drug candidates [41-43].

The four MitoCINs under study are structurally related and based on HCAs or their analog present in the diet. Briefly, the chemical modifications were performed on the phenolic ring substitution pattern, on the type of spacer between the carboxamide and the phenolic ring and on the length of the alkyl linker between the carboxamide and the TPP moiety (Figure 1). The selected compounds feature different aromatic ring substituent patterns (dihydroxy (catechol) or trihydroxy (pyrogallol) moieties), lengths of alkyl linker (6- $(n=1), 8-(n=2)$ and 10-carbon linker $(n=3))$ and type of the spacer between the carboxamide and the aromatic nucleus (ethylene $\left(\mathrm{R}^{\prime}=-\mathrm{H}_{2} \mathrm{C}-\mathrm{CH}_{2}-\right)$ or vinyl group 
$\left.\left(\mathrm{R}^{\prime}=-\mathrm{HC}=\mathrm{CH}-\right)\right)$. (Figure 1) The importance of the diverse structural motifs in MItoCIN cytotoxicity was explored in this work.

We initially evaluated the cytotoxic profile of the four MitoCINs by determining their effects on cell mass, metabolic activity, and intracellular ATP levels in HepG2 and differentiated SH-SY5Y cells. Our results showed that $\mathrm{MC}_{3}$ presented toxicity above 12.5 and $50 \mu \mathrm{M}$ in the HepG2 and differentiated SH-SY5Y cells, respectively. MC $_{6.2}$ showed about 2 times more cytotoxicity in the same cell lines, namely at 6.3 and $25 \mu \mathrm{M}$, respectively. MC4 was the least toxic molecule, not showing toxicity in HepG2 cells and only displaying toxicity in the differentiated SH-SY5Y cells above $100 \mu \mathrm{M}$. $\mathrm{MC}_{7.2}$ also showed low cytotoxicity at concentrations above $100 \mu \mathrm{M}$ in both cell lines (Figures 2-4).

In general, MitoCINs showed a similar or higher cytotoxicity than the parental compounds and lower cytotoxicity than the alkylTPP substructures. In fact, no cytotoxicity was observed in the following parental compounds in the HepG2 and differentiated SH-SY5Y cells: caffeic acid, hydrocaffeic acid and hydro.-TriOH. TriOH reduced cell viability when tested at concentrations higher than $25 \mu \mathrm{M}$ in the differentiated SH-SY5Y cells. Regarding the alkylTPP molecules, the order of cytotoxicity was established as TPP-C6 $<$ TPP-C $8<$ TPP-C10. This data suggests that the cytotoxicity of the MitoCINs under study may be associated with the lipophilicity of the spacer and/or the presence of a TPP moiety and has little, if any, association with the presence of catechol or pyrogallol moieties, as previously described [54]. It should be noted that the extension of $\mathrm{TPP}^{+}$derivative anchorage to the mitochondrial internal membrane is dependent upon their overall lipophilicity, which is mainly modulated by the length of the linker unit and also by the functionalization of the bioactive molecule.

Importantly, we observed higher cytotoxicity from both MitoQ and $\mathrm{SkQ}_{1}$ compared to resveratrol and $\mathrm{CoQ}_{10}$, or to MitoCINs at concentrations above $1 \mu \mathrm{M}$, in the HepG2 and differentiated SH-SY5Y cells (Figures 2-4). In agreement with this finding, Reddy et al. demonstrated that MitoQ concentrations above $0.3 \mu \mathrm{M}$ are toxic to neuronal cells [55], indicating that optimizing MitoQ dosage is a critical step for balancing toxicity and efficacy [56]. Additionally, Sukhanova et al. also demonstrated that the accumulation of MitoQ and $\mathrm{SkQ}_{1}$ in isolated yeast mitochondria can lead to toxic events related to prooxidant effects, depending on the dose [57], reinforcing the importance of developing mitochondrial compounds with lower toxicity and higher efficacy.

A summary of the data obtained in this study was built using violin plots. Figure S17 shows a compilation of cell viability studies, aggregating cell mass, metabolic activity and ATP concentrations measured in HepG2 (panel A) and differentiated SH-SY5Y (panel B) cells after being treated with MitoCINs, quinone-based mitochondria-targeted and non-targeted antioxidants at different concentrations. Each data point corresponds to the average value for the cell viability endpoints measured after treatment. The figure shows that the cell responses to different treatments notably varied at higher concentrations (broader distributions after $25 \mu \mathrm{M}$ for HepG2 and $50 \mu \mathrm{M}$ for SH-SY5Y), reinforcing the compounds' different toxicity profiles. Furthermore, this figure shows that experimental cytotoxicity endpoints appeared to be positively correlated i.e., under a given treatment, these measurements tended to cluster together.

By comparing data on the cytotoxicity of the MitoCINs in HepG2 and differentiated SH-SY5Y cells, based on decreased cell mass, metabolic activity and ATP, a toxicity ranking was established: $\mathrm{MC}_{4}<\mathrm{MC}_{7.2}<\mathrm{MC}_{3}<\mathrm{MC}_{6.2}$, as observed individually for each assay in Table 1 . Notably, $\mathrm{MC}_{4}$ not only did not show any cytotoxic effect between 1-100 $\mu \mathrm{M}$ in the HepG2 and differentiated SH-SY5Y cells, which was in line with our previous results [23,25], but also improved several of the cellular parameters analyzed in this work. After analyzing the relationship between structure and toxicity, we can propose that the lower alkyl chain (C6-alkyl chain) and pyrogallol aromatic pattern are relevant substructures with which to further develop safer mitochondriotropic antioxidants.

As previously described, the presence of the TPP cation and a lipophilic spacer is essential for efficient mitochondrial accumulation, but a suitable lipophilic balance must be 
obtained to reduce the toxicity of mitochondrial-targeted antioxidants [54]. Particularly, we found that in cinnamic compounds or analogs, the catechol vs. pyrogallol replacement in combination with the type of spacer and a suitable length of the alkyl chain can clearly modify their redox behavior towards mitochondrial components, significantly affecting their biological outcome. In fact, the catecholic compounds $\mathrm{MC}_{3}$ and $\mathrm{MC}_{6.2}$ could be oxidized in situ to quinone, a species that can intervene in redox cycles, leading to an increase in ROS intracellular generation and, consequently, an increase in harmful cellular effects [16]. The current work clarified the relevance of the pyrogallol group, namely in $\mathrm{MC}_{4}$ and $\mathrm{MC}_{7.2}$, to modulate the mentioned redox cycle circumventing the cytotoxic events inherent in this type of compound.

Considering the effect of selected MitoCINs on mitochondrial function, our results showed that non-cytotoxic concentrations of $\mathrm{MC}_{3}, \mathrm{MC}_{6.2}, \mathrm{MC}_{4}$ and $\mathrm{MC}_{7.2}$ promoted an apparent loss of $\Delta \Psi$ in HepG2 and differentiated SH-SY5Y cells (Figure S8B), most likely as a consequence of their accumulation in the mitochondrial matrix, as previously described for lipophilic triphenylphosphonium cations [58] and other mitochondria-targeted compounds, namely MitoQ, MitoE and MitoTempol [59]. In fact, lipophilic TPP cationic derivatives are rapidly and extensively taken up in vivo by mitochondria in a process driven by the large negative-inside $\Delta \Psi \mathrm{m}$. Although the uptake mechanism is still not well understood, the extent of the accumulation of a $\mathrm{TPP}^{+}$based derivative depends on the plasma $\Delta \Psi$ and $\Delta \Psi \mathrm{m}$, the volume of the cell, the external media and the number of mitochondria within a given cell [59]. Consequently, the amount of compound accumulated in mitochondria is dependent on the cell type and, accordingly, can explain the different effects of the TPP-based compounds on HepG2 and differentiated SH-SY5Y cells. The drug-metabolic capacity of HepG2 $[60,61]$ cannot be excluded as a factor contributing to the specific effects of all the compounds tested in this study. On the other hand, we found that non-cytotoxic concentrations of $\mathrm{MC}_{3}, \mathrm{MC}_{6.2}, \mathrm{MC}_{4}$ and $\mathrm{MC}_{7.2}$ reduced the mitochondrial membrane potential in the HepG2 and differentiated SH-SY5Y cells, with a higher magnitude of effects compared to non-cytotoxic concentrations of MitoQ, resveratrol or $\mathrm{SkQ}_{1}$, resveratrol, and $\mathrm{CoQ}_{10}$, respectively, probably as a consequence of a higher accumulation on the mitochondrial matrix compared to non-cytotoxic concentrations of the other TPP-based compounds and commercial antioxidants. Interestingly, by analyzing non-cytotoxic concentrations of catechol and pyrogallol derivatives, it was noticeable that the MitoCINs conjugated with TPP-C10 resulted in a greater decrease in mitochondrial membrane potential compared to compounds conjugated with a TPP-C8 and TPP-C6 linker in the differentiated SH-SY5Y cells. In fact, a decrease in mitochondrial membrane potential does not always mean cytotoxicity. Still, our data on intracellular ATP levels suggest that some of the compounds' effects on membrane potential are related to a decrease in ATP levels as well. In sum, these results also suggest that the length of the TPP alkyl chain can influence the capacity of these compounds to be accumulated. In sum, these results also suggest that the length of the TPP alkyl chain can influence the capacity of these compounds to be accumulated and cause alterations in mitochondria.

Regarding the cellular OCR and ECAR parameters, we concluded that $\mathrm{MC}_{3}, \mathrm{MC}_{6.2}$, $\mathrm{MC}_{4}$ and $\mathrm{MC}_{7.2}$ did not present significant mitochondrial toxicity at concentrations up to $100 \mu \mathrm{M}$ in the HepG2 cells (Figure 6). By contrast, a decrease in mitochondrial respiration in the differentiated SH-SY5Y cells treated with $\mathrm{MC}_{6.2}$ was found, which was observed through the decrease in ATP production-linked, proton leak, basal, maximal and stressed OCR compared to the untreated cells (Figure 7A-K). The difference in effects between the two types of cell probably occurred due to the amount of compound accumulated inside the mitochondria [59]. The reduction in maximal and stressed OCR suggests an impairment of non-phosphorylative respiration. At the same time, the inhibition of production-linked ATP might indicate an effect in the mitochondrial phosphorylative system at concentrations lower than those that caused the effects on cell viability. It should be noted that the decrease in the proton leak and basal OCR and the increase in the basal ECAR observed in the differentiated SH-SY5Y cells treated with $\mathrm{MC}_{6.2}$ probably occurred as a consequence 
of membrane-related effects. The decrease in the mitochondrial membrane potential may have resulted from the accumulation of this compound in the mitochondria and as a consequence of interactions with non-phosphorylative respiration, either at the protein or membrane levels. $\mathrm{MC}_{3}$ did not affect mitochondrial bioenergetics in the differentiated $\mathrm{SH}-$ SY5Y cells at the concentrations used. However, at the same concentrations, $\mathrm{MC}_{3}$ presented higher values of proton leak-associated OCR and lower values of ECAR, compared to the maximal non-cytotoxic concentrations of the respective alkylTPP cation (TPP-C8).

Nonetheless, $50 \mu \mathrm{M}$ of pyrogallol-based derivative $\mathrm{MC}_{4}$ improved mitochondrial bioenergetics in the differentiated SH-SY5Y (but not HepG2) cells compared to untreated cells, as was manifested by the significant increase in the ATP production-linked OCR (Figure $7 \mathrm{C}$ ). In parallel, $\mathrm{MC}_{4}$ and $\mathrm{MC}_{7.2}$ also increased the proton leakage through the mitochondrial inner membrane (IMM) (Figure 7E) resulting from a membrane permeabilization effect or a proton shuttling activity, which may consequently have reduced the mitochondrial membrane potential in these cells (Figure 5). The increase in proton leak-based OCR (Figure 7E) was not only due to the effect of the TPP cations, since this parameter was significantly higher in the cells treated with $\mathrm{MC}_{4}$ and $M C_{7.2}$ compared to the cells treated with their corresponding alkylTPP compound. These data suggest that the effects on mitochondrial function resulted from the balance of their overall lipophilicity, which is linked to the length of the linker unit, the type of spacer and the structure of the bioactive molecule.

$\mathrm{MC}_{3}$ and $\mathrm{MC}_{6.2}$ affected mitochondrial respiration more significantly than resveratrol or $\mathrm{CoQ}_{10}$ at equal or lower concentrations $\left(\mathrm{MC}_{3}: 25-50 \mu \mathrm{M}\right.$ and $\mathrm{MC}_{6.2}: 12.5-25 \mu \mathrm{M}$ vs. $\mathrm{CoQ}_{10}: 50-100 \mu \mathrm{M}$ and resveratrol: $25-50 \mu \mathrm{M}$ ). The decline in mitochondrial respiration was confirmed by the decrease in ATP production-linked OCR, proton leak-associated OCR, basal, maximal and stressed OCR values comparatively to resveratrol or CoQ 10 . $\mathrm{MC}_{3}$ and $\mathrm{MC}_{6.2}$ also affected mitochondrial respiration more significantly than MitoQ and $\mathrm{SkQ}_{1}$, albeit at concentrations 12 to 50 times higher than these two mitochondrial-targeted antioxidants $\left(\mathrm{MC}_{3}: 25-50 \mu \mathrm{M}\right.$ and $\mathrm{MC}_{6.2}: 12.5-25 \mu \mathrm{M}$ vs. SkQ1: $1.5-3.1 \mu \mathrm{M}$ and MitoQ: 0.5-1 $\mu \mathrm{M})$.

Analyzing in detail the effects of $M C_{4}$ and $M C_{7.2}$ compared to MitoQ and $\mathrm{SkQ}_{1}$, it is clear that at maximal non-cytotoxic concentrations of these four mitochondrial-targeted antioxidants, no mitochondrial toxicity was observed in the HepG2 and differentiated SHSY5Y cells, although $\mathrm{MC}_{4}$ and $\mathrm{MC}_{7.2}$ showed around 100 and 1000 times less cytotoxicity in these two cell lines than $\mathrm{SkQ}_{1}$ and MitoQ, respectively $\left(\mathrm{MC}_{4}: 50-100 \mu \mathrm{M}\right.$ and $\mathrm{MC}_{7.2}$ : 25-100 $\mu \mathrm{M}$ vs. SkQ1: $0.5-3.1 \mu \mathrm{M}$ and MitoQ: 0.5-1 $\mu \mathrm{M})$. Despite this, $\mathrm{MC}_{4}$ decreased basal respiration and proton leak-associated OCR in the differentiated SH-SY5Y cells compared to resveratrol and $\mathrm{CoQ}_{10}$ at concentrations two times higher or identical to these two antioxidants, respectively $\left(\mathrm{MC}_{4}: 50-100 \mu \mathrm{M}\right.$ vs. resveratrol: $25-50 \mu \mathrm{M}$ and $\mathrm{CoQ}_{10}$ : 50-100 $\mu \mathrm{M})$. These results suggest that, despite being a cationic molecule, $\mathrm{MC}_{4}$ induced less proton leakage through the IMM, compared to $\mathrm{CoQ}_{10}$ and resveratrol.

In conclusion, $\mathrm{MC}_{4}$ and $\mathrm{MC}_{7.2}$ presented up to eight times less cytotoxicity than $\mathrm{MC}_{3}$ and $\mathrm{MC}_{6.2}$ and around 100 to 1000 times less cytotoxicity than $\mathrm{SkQ}_{1}$ and MitoQ in HepG2 and differentiated SH-SY5Y cells. Maximal non-cytotoxic concentrations (50 or $100 \mu \mathrm{M}$ ) of $\mathrm{MC}_{4}$ and $\mathrm{MC}_{7.2}$ did not induce any mitochondrial toxicity in HepG2 or differentiated SH-SY5Y cells. Additionally, the maximal non-cytotoxic concentrations of $\mathrm{SkQ}_{1}$ and MitoQ were around 100 to 1000 times less than the corresponding concentration of $\mathrm{MC}_{4}$ and $\mathrm{MC}_{7.2}$. In sum, based on the cytotoxicity cellular data and mitochondrial functional parameters analyzed, $\mathrm{MC}_{4}$ and $\mathrm{MC}_{7.2}$ emerged as potential drug candidates with a potential therapeutic application in mitochondrial oxidative stress-related diseases, particularly in hepatic and neurodegenerative diseases, presenting a better safety profile than the two quinone-based mitochondria-targeted molecules used for comparison.

Supplementary Materials: The following are available online at https:/ / www.mdpi.com/article/ 10.3390/biom11111605/s1, Figure S1: Effect of parental antioxidants and alkylTPP compounds on cell mass, Figure S2: Effect of parental antioxidants and alkylTPP compounds on metabolic activity, 
Figure S3: Effect of parental antioxidants and alkylTPP compounds on ATP intracellular concentrations, Figure S4: Comparison between the effects of MitoCINs, quinone-based mitochondria-targeted, non-targeted antioxidants, parental antioxidants and alkylTPP compounds on cell mass, Figure S5: Comparison between the effects of MitoCINs, quinone-based mitochondria-targeted, non-targeted antioxidants, parental antioxidants and alkylTPP compounds on metabolic activity, Figure S6: Comparison between the effects of MitoCINs, quinone-based mitochondria-targeted, non-targeted antioxidants, parental antioxidants and alkylTPP compounds on ATP intracellular concentrations, Figure S7: Comparison between the effects of MitoCINs, quinone-based mitochondria-targeted, non-targeted antioxidants, parental antioxidants and alkylTPP compounds on TMRM intensity fluorescence, Figure S8: Effect of parental antioxidants and alkylTPP compounds on TMRM intensity fluorescence, Figure S9: Comparison between the effects of MitoCINs, quinone-based mitochondria-targeted and non-targeted antioxidants on oxygen consumption rate (OCR) and extracellular acidification rate (ECAR) in human caucasian hepatocyte carcinoma (HepG2) cells, Figure S10: Comparison between the effects of MitoCINs, quinone-based mitochondria-targeted and non-targeted antioxidants on oxygen consumption rate (OCR) and extracellular acidification rate (ECAR) in differentiated human neuroblastoma (SH-SY5Y) cells, Figure S11: Effect of parental antioxidants and alkylTPP compounds on oxygen consumption rate (OCR) and extracellular acidification rate (ECAR), Figure S12: Effect of parental antioxidants and alkylTPP compounds on oxygen consumption rate (OCR) and extracellular acidification rate (ECAR), Figure S13: Comparison between the effects of MitoCINs and parental antioxidants on oxygen consumption rate (OCR) and extracellular acidification rate (ECAR) in human caucasian hepatocyte carcinoma (HepG2) cells, Figure S14: Comparison between the effects of MitoCINs and parental antioxidants on oxygen consumption rate (OCR) and extracellular acidification rate (ECAR) in differentiated human neuroblastoma (SH-SY5Y) cells, Figure S15: Comparison between the effects of MitoCINs and alkylTPP compounds on oxygen consumption rate (OCR) and extracellular acidification rate (ECAR) in human caucasian hepatocyte carcinoma (HepG2) cells, Figure S16: Comparison between the effects of MitoCINs and alkylTPP compounds on oxygen consumption rate (OCR) and extracellular acidification rate (ECAR)in differentiated human neuroblastoma (SH-SY5Y) cells, Figure S17: Violin plot distributions of the average experimental points for HepG2 (panel A) and SH-SY5Y (panel B) viability, namey, cell mass (SRB), metabolic activity (resazurin) and ATP, under different compound treatments (MitoCINs, quinone-based mitochondria-targeted and non-targeted antioxidants) grouped by similar concentration.

Author Contributions: C.F. and S.B. synthesized the MitoCINs and P.S. synthesized the MitoQ and $\mathrm{SkQ}_{1}$. C.D.V., J.D.M., B.G. and J.T. performed the cellular studies described in this manuscript. A.J.C.V. and J.F.S.D. developed the system to integrate heterogeneous datasets into standardized dataset architecture, automate data visualization and perform the statistical analysis. F.S.G.S., P.J.O. and F.B. designed the experiments. P.J.O., F.B. and A.M.S.S. conceived and supervised the study. C.D.V., P.J.O., F.B., F.S.G.S., J.T. and C.F. wrote the manuscript. All authors critically revised the final form of the manuscript. All authors have read and agreed to the published version of the manuscript.

Funding: This article has been developed in the framework of "38429 TAG2020: Investigação de antioxidantes inovadores para introdução em cosmética e saúde animal" by MITOTAG, LDA. Project supported by CENTRO 2020 of PT2020 through the European Regional Development Fund (ERDF).

Institutional Review Board Statement: Not applicable.

Informed Consent Statement: Not applicable.

Data Availability Statement: Data supporting the results are available upon reasonable requests.

Acknowledgments: S. Benfeito (PTDC/MED-QUI/29164/2017) grant is supported by FCT, and P2020 I COMPETE. Pedro Soares research is supported by the European Union's Horizon 2020 research and innovation program under the Marie Sklodowska-Curie grant agreement No 895144. The graphical abstract present in this manuscript contains images from SMART-Servier Medical Art (smart.servier.com (accessed on 16 September 2021)).

Conflicts of Interest: José F. S. Duarte, António M. S. Santos, Paulo J. Oliveira, Fernanda Borges are cofounders of spin-off company MitoTAG (Coimbra, Portugal). No other competing interests exist. The MitoCIN compounds are part of "HYDROXYCINNAMIC DERIVATIVES, METHODS AND USES" patent (WO2018069904; PCT/IB2017/056412; US 2019/0248816) that is authored by F Borges, PJ Oliveira, J. Teixeira, F Cagide, S Benfeito. 


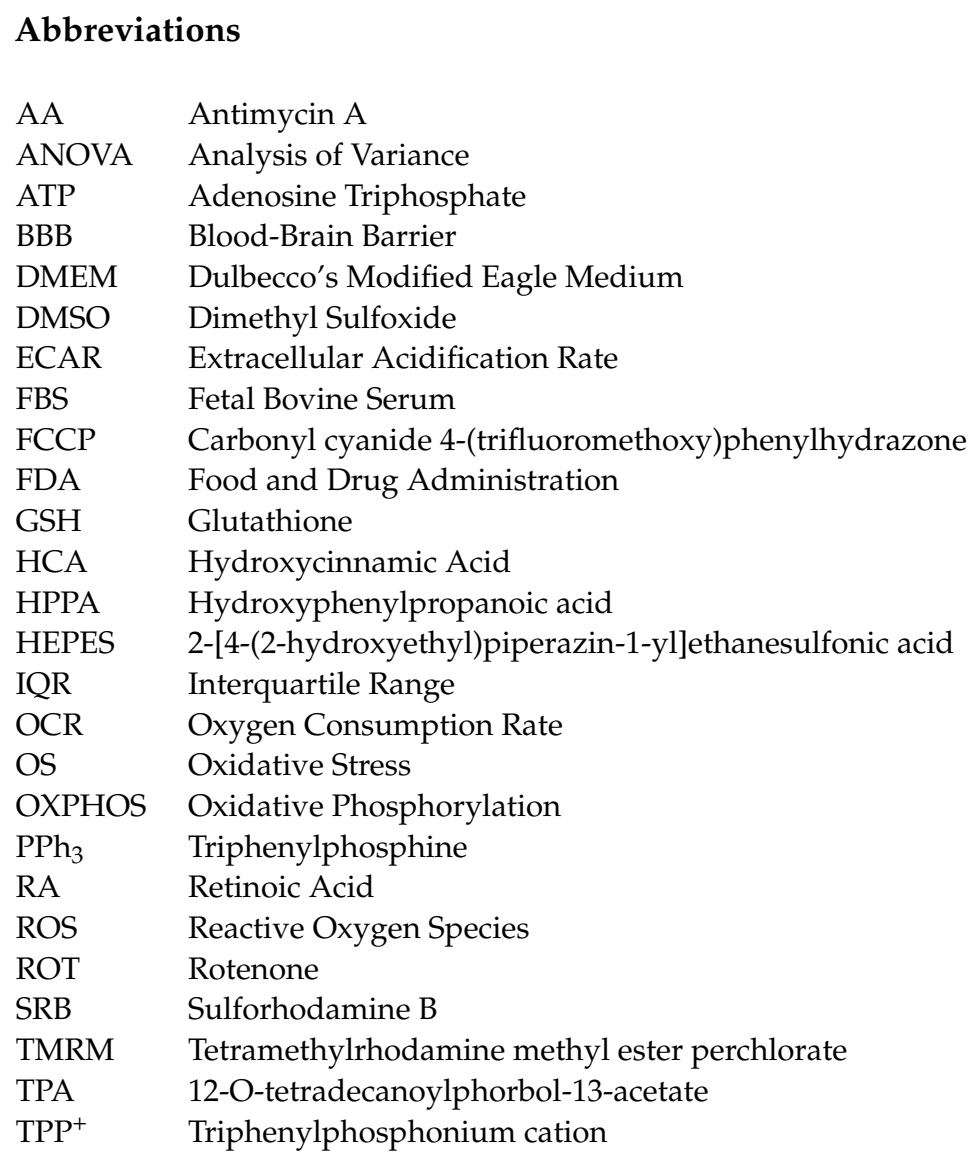

\section{References}

1. Smith, R.A.; Hartley, R.; Cochemé, H.M.; Murphy, M. Mitochondrial pharmacology. Trends Pharmacol. Sci. $2012,33,341-352$. [CrossRef]

2. Kudryavtseva, A.V.; Krasnov, G.S.; Dmitriev, A.; Alekseev, B.Y.; Kardymon, O.; Sadritdinova, A.F.; Fedorova, M.S.; Pokrovsky, A.V.; Melnikova, N.V.; Kaprin, A.D.; et al. Mitochondrial dysfunction and oxidative stress in aging and cancer. Oncotarget 2016, 7, 44879-44905. [CrossRef] [PubMed]

3. Bhatti, J.S.; Bhatti, G.K.; Reddy, P.H. Mitochondrial dysfunction and oxidative stress in metabolic disorders-A step towards mitochondria based therapeutic strategies. Biochim. Biophys. Acta BBA Mol. Basis Dis. 2017, 1863, 1066-1077. [CrossRef]

4. Chistiakov, D.A.; Sobenin, I.A.; Revin, V.V.; Orekhov, A.N.; Bobryshev, Y.V. Mitochondrial aging and age-related dysfunction of mitochondria. BioMed Res. Int. 2014, 2014, 238463. [CrossRef] [PubMed]

5. Battogtokh, G.; Choi, Y.S.; Kang, D.S.; Park, S.J.; Shim, M.S.; Huh, K.M.; Cho, Y.-Y.; Lee, J.Y.; Lee, H.S.; Kang, H.C. Mitochondriatargeting drug conjugates for cytotoxic, anti-oxidizing and sensing purposes: Current strategies and future perspectives. Acta Pharm. Sin. B 2018, 8, 862-880. [CrossRef]

6. Tauskela, J.S. MitoQ-A mitochondria-targeted antioxidant. IDrugs Investig. Drugs J. 2007, 10, 399-412.

7. Kelso, G.F.; Porteous, C.M.; Coulter, C.V.; Hughes, G.; Porteous, W.K.; Ledgerwood, E.C.; Smith, R.A.; Murphy, M.P. Selective targeting of a redox-active ubiquinone to mitochondria within cells: Antioxidant and antiapoptotic properties. J. Biol. Chem. 2001, 276, 4588-4596. [CrossRef]

8. Antonenko, Y.N.; Avetisyan, A.V.; Bakeeva, L.E.; Chernyak, B.V.; Chertkov, V.A.; Domnina, L.V.; Ivanova, O.Y.; Izyumov, D.S.; Khailova, L.S.; Klishin, S.S.; et al. Mitochondria-targeted plastoquinone derivatives as tools to interrupt execution of the aging program. 1. Cationic plastoquinone derivatives: Synthesis and in vitro studies. Biochemistry 2008, 73, 1273-1287. [CrossRef] [PubMed]

9. Cochemé, H.M.; Kelso, G.F.; James, A.M.; Ross, M.F.; Trnka, J.; Mahendiran, T.; Asin-Cayuela, J.; Blaikie, F.H.; Manas, A.-R.B.; Porteous, C.M.; et al. Mitochondrial targeting of quinones: Therapeutic implications. Mitochondrion 2007, 7, S94-S102. [CrossRef]

10. Skulachev, V.P.; Anisimov, V.N.; Antonenko, Y.N.; Bakeeva, L.E.; Chernyak, B.V.; Erichev, V.P.; Filenko, O.F.; Kalinina, N.I.; Kapelko, V.I.; Kolosova, N.G.; et al. An attempt to prevent senescence: A mitochondrial approach. Biochim. Biophys. Acta BBA Bioenerg. 2009, 1787, 437-461. [CrossRef] [PubMed]

11. Gottwald, E.M.; Duss, M.; Bugarski, M.; Haenni, D.; Schuh, C.D.; Landau, E.M.; Hall, A.M. The targeted anti-oxidant MitoQ causes mitochondrial swelling and depolarization in kidney tissue. Physiol. Rep. 2018, 6, e13667. [CrossRef] [PubMed] 
12. James, A.M.; Cochemé, H.M.; Smith, R.A.J.; Murphy, M. Interactions of mitochondria-targeted and untargeted ubiquinones with the mitochondrial respiratory chain and reactive oxygen species. J. Biol. Chem. 2005, 280, 21295-21312. [CrossRef] [PubMed]

13. Doughan, A.K.; Dikalov, S.I. Mitochondrial redox cycling of mitoquinone leads to superoxide production and cellular apoptosis. Antioxid. Redox Signal. 2007, 9, 1825-1836. [CrossRef]

14. Snow, B.J.; Rolfe, F.L.; Lockhart, M.M.; Frampton, C.M.; O'Sullivan, J.D.; Fung, V.; Smith, R.A.; Murphy, M.P.; Taylor, K.M. A double-blind, placebo-controlled study to assess the mitochondria-targeted antioxidant MitoQ as a disease-modifying therapy in Parkinson's disease. Mov. Disord. 2010, 25, 1670-1674. [CrossRef]

15. Sandoval-Acuña, C.; Ferreira, J.; Speisky, H. Polyphenols and mitochondria: An update on their increasingly emerging ROSscavenging independent actions. Arch. Biochem. Biophys. 2014, 559, 75-90. [CrossRef]

16. Fernandes, C.; Pinto, M.; Martins, C.; Gomes, M.J.; Sarmento, B.; Oliveira, P.J.; Remião, F.; Borges, F.M. Development of a PEGylated-based platform for efficient delivery of dietary antioxidants across the blood-brain barrier. Bioconjug. Chem. 2018, 29, 1677-1689. [CrossRef]

17. Crozier, A.; Jaganath, I.B.; Clifford, M.N. Dietary phenolics: Chemistry, bioavailability and effects on health. Nat. Prod. Rep. 2009, 26, 1001-1043. [CrossRef]

18. Singh, M.; Arseneault, M.; Sanderson, T.; Murthy, V.; Ramassamy, C. Challenges for research on polyphenols from foods in Alzheimer's disease: Bioavailability, metabolism, and cellular and molecular mechanisms. J. Agric. Food Chem. 2008, 56, 4855-4873. [CrossRef]

19. Gao, S.; Hu, M. Bioavailability challenges associated with development of anti-cancer phenolics. Mini Rev. Med. Chem. 2010, 10, 550-567. [CrossRef]

20. Boveris, A.; Chance, B. The mitochondrial generation of hydrogen peroxide. General properties and effect of hyperbaric oxygen. Biochem. J. 1973, 134, 707-716. [CrossRef] [PubMed]

21. Turrens, J.F. Mitochondrial formation of reactive oxygen species. J. Physiol. 2003, 552, 335-344. [CrossRef]

22. Murphy, M.P. How mitochondria produce reactive oxygen species. Biochem. J. 2009, 417, 1-13. [CrossRef] [PubMed]

23. Teixeira, J.; Cagide, F.; Benfeito, S.; Soares, P.; Garrido, J.; Baldeiras, I.; Ribeiro, J.A.; Pereira, C.M.; Silva, A.F.; Andrade, P.B.; et al. Development of a mitochondriotropic antioxidant based on caffeic acid: Proof of concept on cellular and mitochondrial oxidative stress models. J. Med. Chem. 2017, 60, 7084-7098. [CrossRef] [PubMed]

24. Teixeira, J.C.S.; Soares, P.; Benfeito, S.; Gaspar, A.; Garrido, J.; Murphy, M.P.; Borges, F. Rational discovery and development of a mitochondria-targeted antioxidant based on cinnamic acid scaffold. Free Radic. Res. 2012, 46, 600-611. [CrossRef]

25. Benfeito, S.; Oliveira, C.; Fernandes, C.; Cagide, F.; Teixeira, J.; Amorim, R.; Garrido, J.; Martins, C.; Sarmento, B.; Silva, R.; et al. Fine-tuning the neuroprotective and blood-brain barrier permeability profile of multi-target agents designed to prevent progressive mitochondrial dysfunction. Eur. J. Med. Chem. 2019, 167, 525-545. [CrossRef] [PubMed]

26. Hernández-Camacho, J.D.; Bernier, M.; López-Lluch, G.; Navas, P. Coenzyme Q10 supplementation in aging and disease. Front. Physiol. 2018, 9, 44. [CrossRef]

27. Forman, H.J.; Zhang, H. Targeting oxidative stress in disease: Promise and limitations of antioxidant therapy. Nat. Rev. Drug Discov. 2021, 20, 689-709. [CrossRef] [PubMed]

28. Cvenkel, B.; Kolko, M. Current medical therapy and future trends in the management of glaucoma treatment. J. Ophthalmol. 2020, 2020, 6138132. [CrossRef]

29. Navarro-Cruz, A.R.; Ayala, R.R.Y.; Ochoa-Velasco, C.; Brambila, E.; Avila-Sosa, R.; Pérez-Fernández, S.; Morales-Medina, J.C.; Aguilar-Alonso, P. Effect of chronic administration of resveratrol on cognitive performance during aging process in rats. Oxid. Med. Cell. Longev. 2017, 2017, 8510761. [CrossRef]

30. Li, Y.-R.; Li, S.; Lin, C.-C. Effect of resveratrol and pterostilbene on aging and longevity. BioFactors 2018, 44, 69-82. [CrossRef]

31. Sawda, C.; Moussa, C.; Turner, R.S. Resveratrol for Alzheimer's disease. Ann. N. Y. Acad. Sci. 2017, 1403, 142-149. [CrossRef] [PubMed]

32. Albani, D.; Polito, L.; Forloni, G. Sirtuins as novel targets for Alzheimer's disease and other neurodegenerative disorders: Experimental and genetic evidence. J. Alzheimer Dis. 2010, 19, 11-26. [CrossRef]

33. Anekonda, T.S. Resveratrol-A boon for treating Alzheimer's disease? Brain Res. Rev. 2006, 52, 316-326. [CrossRef]

34. Gräff, J.; Kahn, M.; Samiei, A.; Gao, J.; Ota, K.T.; Rei, D.; Tsai, L.-H. A dietary regimen of caloric restriction or pharmacological activation of SIRT1 to delay the onset of neurodegeneration. J. Neurosci. 2013, 33, 8951-8960. [CrossRef] [PubMed]

35. Giorgi, C.; Marchi, S.; Simoes, I.C.; Ren, Z.; Morciano, G.; Perrone, M.; Patalas-Krawczyk, P.; Borchard, S.; Jędrak, P.; Pierzynowska, K.; et al. Mitochondria and reactive oxygen species in aging and age-related diseases. Int. Rev. Cell Mol. Biol. 2018, 340, 209-344. [CrossRef]

36. Christensen, E.R.; Stegger, M.; Jensen-Fangel, S.; Laursen, A.L.; Ostergaard, L. Mitochondrial DNA levels in fat and blood cells from patients with lipodystrophy or peripheral neuropathy and the effect of 90 days of high-dose coenzyme Q treatment: $A$ randomized, double-blind, placebo-controlled pilot study. Clin. Infect. Dis. 2004, 39, 1371-1379. [CrossRef]

37. McGarry, A.; McDermott, M.; Kieburtz, K.; De Blieck, E.A.; Beal, F.; Marder, K.; Ross, C.; Shoulson, I.; Gilbert, P.; Mallonee, W.M.; et al. A randomized, double-blind, placebo-controlled trial of coenzyme Q10 in Huntington disease. Neurology 2017, 88, 152-159. [CrossRef]

38. Liu, J.; Wang, L.-N. Mitochondrial enhancement for neurodegenerative movement disorders: A systematic review of trials involving creatine, coenzyme Q10, idebenone and mitoquinone. CNS Drugs 2013, 28, 63-68. [CrossRef] 
39. Jakubczyk, K.; Skonieczna-Żydecka, K.; Kałduńska, J.; Stachowska, E.; Gutowska, I.; Janda, K. Effects of resveratrol supplementation in patients with non-alcoholic fatty liver disease-A meta-analysis. Nutrients 2020, 12, 2435. [CrossRef]

40. De Ligt, M.; Bergman, M.; Fuentes, R.M.; Essers, H.; Moonen-Kornips, E.; Havekes, B.; Schrauwen-Hinderling, V.B.; Schrauwen, P. No effect of resveratrol supplementation after 6 months on insulin sensitivity in overweight adults: A randomized trial. Am. J. Clin. Nutr. 2020, 112, 1029-1038. [CrossRef] [PubMed]

41. Presgraves, S.P.; Ahmed, T.; Borwege, S.; Joyce, J.N. Terminally differentiated SH-SY5Y cells provide a model system for studying neuroprotective effects of dopamine agonists. Neurotox. Res. 2003, 5, 579-598. [CrossRef] [PubMed]

42. Clothier, R.; Gómez-Lechón, M.; Kinsner-Ovaskainen, A.; Kopp-Schneider, A.; O'Connor, J.; Prieto, P.; Stanzel, S. Comparative analysis of eight cytotoxicity assays evaluated within the ACuteTox project. Toxicol. Vitr. 2013, 27, 1347-1356. [CrossRef]

43. Kizhedath, A.; Wilkinson, S.; Glassey, J. Assessment of hepatotoxicity and dermal toxicity of butyl paraben and methyl paraben using HepG2 and HDFn in vitro models. Toxicol. Vitr. 2019, 55, 108-115. [CrossRef] [PubMed]

44. Donato, M.; Tolosa, L.; Gómez-Lechón, M.J. Culture and functional characterization of human hepatoma HepG2 cells. In Protocols in In Vitro Hepatocyte Research; Springer Science and Business Media LLC: Berlin/Heidelberg, Germany, 2014; Volume 1250, pp. 77-93.

45. Khailova, L.S.; Nazarov, P.A.; Sumbatyan, N.; Korshunova, G.A.; Rokitskaya, T.; Dedukhova, V.I.; Antonenko, Y.N.; Skulachev, V. Uncoupling and toxic action of alkyltriphenylphosphonium cations on mitochondria and the bacterium Bacillus subtilis as a function of alkyl chain length. Biochemistry 2015, 80, 1589-1597. [CrossRef]

46. Korshunova, G.A.; Shishkina, A.V.; Skulachev, M.V. Design, synthesis, and some aspects of the biological activity of mitochondriatargeted antioxidants. Biochemistry 2017, 82, 760-777. [CrossRef]

47. Barbosa, D.J.; Capela, J.P.; Silva, R.; Vilas-Boas, V.; Ferreira, L.; Branco, P.; Fernandes, E.; Bastos, M.D.L.; Carvalho, F. The mixture of "ecstasy" and its metabolites is toxic to human SH-SY5Y differentiated cells at in vivo relevant concentrations. Arch. Toxicol. 2013, 88, 455-473. [CrossRef]

48. Silva, F.S.; Starostina, I.G.; Ivanova, V.V.; Rizvanov, A.A.; Oliveira, P.J.; Pereira, S.P. Determination of metabolic viability and cell mass using a tandem resazurin/sulforhodamine B assay. Curr. Protoc. Toxicol. 2016, 68, 2-24. [CrossRef]

49. Creed, S.; McKenzie, M. Measurement of mitochondrial membrane potential with the fluorescent dye tetramethylrhodamine methyl ester (TMRM). Methods Mol. Biol. 2019, 1928, 69-76. [CrossRef] [PubMed]

50. Murphy, M.P. Targeting lipophilic cations to mitochondria. Biochim. Biophys. Acta BBA Bioenerg. 2008, 1777, 1028-1031. [CrossRef]

51. Bond, S.T.; Kim, J.; Calkin, A.; Drew, B.G. The antioxidant moiety of MitoQ imparts minimal metabolic effects in adipose tissue of high fat fed mice. Front. Physiol. 2019, 10, 543. [CrossRef]

52. Bolton, J.L.; Dunlap, T. Formation and biological targets of quinones: Cytotoxic versus cytoprotective effects. Chem. Res. Toxicol. 2017, 30, 13-37. [CrossRef]

53. Feng, Z.; Nadikudi, M.; Woolley, K.; Hemasa, A.; Chear, S.; Smith, J.; Gueven, N. Bioactivity profiles of cytoprotective short-chain quinones. Molecules 2021, 26, 1382. [CrossRef]

54. Teixeira, J.; Oliveira, C.; Amorim, R.; Cagide, F.; Garrido, J.; Ribeiro, J.A.; Pereira, C.M.; Silva, A.F.; Andrade, P.B.; Oliveira, P.J.; et al. Development of hydroxybenzoic-based platforms as a solution to deliver dietary antioxidants to mitochondria. Sci. Rep. 2017, 7, 6842. [CrossRef] [PubMed]

55. Reddy, P.H.; Beal, M.F. Amyloid beta, mitochondrial dysfunction and synaptic damage: Implications for cognitive decline in aging and Alzheimer's disease. Trends Mol. Med. 2008, 14, 45-53. [CrossRef]

56. Reddy, P.H. Mitochondrial medicine for aging and neurodegenerative diseases. NeuroMolecular Med. 2008, 10, 291-315. [CrossRef]

57. Sukhanova, E.I.; Trendeleva, T.A.; Zvyagilskaya, R.A. Interaction of yeast mitochondria with fatty acids and mitochondriatargeted lipophilic cations. Biochemistry 2010, 75, 139-144. [CrossRef] [PubMed]

58. Trnka, J.; Elkalaf, M.; Anděl, M. Lipophilic triphenylphosphonium cations inhibit mitochondrial electron transport chain and induce mitochondrial proton leak. PLoS ONE 2015, 10, e0121837. [CrossRef]

59. Reily, C.; Mitchell, T.; Chacko, B.K.; Benavides, G.A.; Murphy, M.P.; Darley-Usmar, V.M. Mitochondrially targeted compounds and their impact on cellular bioenergetics. Redox Biol. 2013, 1, 86-93. [CrossRef] [PubMed]

60. Yokoyama, Y.; Sasaki, Y.; Terasaki, N.; Kawataki, T.; Takekawa, K.; Iwase, Y.; Shimizu, T.; Sanoh, S.; Ohta, S. Comparison of drug metabolism and its related hepatotoxic effects in HepaRG, cryopreserved human hepatocytes, and HepG2 cell cultures. Biol. Pharm. Bull. 2018, 41, 722-732. [CrossRef]

61. Choi, J.M.; Oh, S.J.; Lee, S.Y.; Im, J.H.; Oh, J.M.; Ryu, C.S.; Kwak, H.C.; Lee, J.-Y.; Kang, K.W.; Kim, S.K. HepG2 cells as an in vitro model for evaluation of cytochrome P450 induction by xenobiotics. Arch. Pharm. Res. 2014, 38, 691-704. [CrossRef] [PubMed] 